\begin{tabular}{|c|l|}
\hline Title & Tensile strength of frozen soil in the temperature range of the frozen fringe \\
\hline Author(s) & A kagawa, Satoshi; Nishisato, Kohei \\
\hline Citation & $\begin{array}{l}\text { Cold Regions Science and Technology, 57(1), 13-22 } \\
\text { https://doi.org/10.1016/.coldregions.2009.01.002 }\end{array}$ \\
\hline Issue Date & 2009-06 \\
\hline Doc URL & http://hdl.handle.net/2115/38593 \\
\hline Type & article (author version) \\
\hline File Information & $57-1$ p13 22.pdf \\
\hline
\end{tabular}

Instructions for use 


\title{
Tensile Strength of Frozen Soil in the Temperature Range of the Frozen Fringe
}

\author{
Satoshi Akagawa ${ }^{\text {a,*}}$, Kohei Nishisato ${ }^{b}$ \\ ${ }^{\text {a }}$ Hokkaido University, Sapporo, Japan \\ ${ }^{\mathrm{b}}$ Prefectural Government of Iwate, Morioka, Japan
}

\begin{abstract}
Frost heaving is a discontinuous phenomenon. It starts from rupture in the partially frozen soil called the frozen fringe and then segregation of an ice lens follows in the rupture. Macroscopically, the above-mentioned cycle repeats consistently as soil freezes. The rupture of the frozen fringe should govern the initial conditions of ice lens growth; however, it has not been studied so far. In this paper, the rupture is studied assuming that it has a close relationship with the tensile strength of the frozen fringe. The compressive strength of frozen soil was well-studied in the last century. However, the tensile strength of frozen soil in frozen fringe temperature range, i.e. 0 to $-2{ }^{\circ} \mathrm{C}$, has not yet been explored. Disturbed, reconsolidated, and frozen diluvial silt called Dotan in Japan was used as the test specimen. A newly developed tensile test apparatus was used. Fifteen tensile tests were conducted in the temperature range of +0.6 to $-1.31^{\circ} \mathrm{C}$. A steep rise in the tensile strength in the
\end{abstract}

\footnotetext{
* Corresponding Author, Tel:+81-11-706-7246, Fax:+81-11-706-7249, E-mail address: akagawa@eng.hokudai.ac.jp
} 
frozen fringe temperature range was observed, being 20 to 70 times higher than that in the unfrozen state. A mechanism of explaining the steep rise in tensile strength is discussed along with the unfrozen water content of Dotan and ice tensile strength, and a simplified soil structure model. The tensile strength of the frozen fringe seems to be primarily due to the tensile strength of the pore ice framework.

Keywords: tensile strength, frozen fringe, ice lens, frost heave, pore ice 


\section{Introduction}

After the remarkable pioneering works made by Taber (1929) and Beskow (1935), many active and enthusiastic scientists and engineers have conducted intense scientific research on frost heave. However, even in the twenty-first century, we do not have a complete scientific understanding of the frost heave mechanism. Black and Hardenberg (1991) presented a history of research of the frost heave mechanism including the approach from Cornell University. A few promising idealized frost heave mechanisms were proposed in the 1970s and 1980s by Gilpin (1979, 1980), Miller (1978), and Takagi (1980). In 1985, the $5^{\text {th }}$ International Symposium on Ground Freezing was held in Sapporo, and a major future research direction on the study of the frost heave mechanism was proposed: that is "no more models and return to experiments.” People working on this scientific topic realized during the symposium that the proposed mechanisms contain many assumptions that need to be clarified empirically.

Unfortunately, interest in both the theoretical and empirical aspects of this research area decreased during the 1990s. With this paper, we intend to reinitiate experimental research focusing on single ice lens initiation during frost heave. In other words, frost heaving is commonly perceived as a continuous phenomenon; instead, it is the repetition of a discontinuous phenomenon, i.e. new ice lens initiation and growth. Therefore, ice lens initiation that is controlled by soil cracking has to be clarified scientifically. Previous interpretations of research results suggested that ice lens initiation does not need a remarkable force to open a crack for the newly forming ice lens. In other words, zero effective pressure was 
assumed as a new ice lens initiation condition. However, a pioneering work done by Haynes (1978) demonstrated the tensile strength of Fairbanks silt at -0.1 and $-1.7^{\circ} \mathrm{C}$. In this paper, we demonstrate that the tensile strength of frost susceptible soil in the frozen fringe temperature range, i.e. 0 to $-2{ }^{\circ} \mathrm{C}$, is an important factor during the ice lens initiation process.

\section{Experiment}

Previous research focusing on the tensile strength of frozen soil includes works such as Vialov et al. (1965), Haynes et al. (1975), Lade et al. (1980), Bragg and Andersland (1980), and Zhu and Carbee (1985). All of these works, however, covered the tensile strength of frozen soil below $-5^{\circ} \mathrm{C}$. An exception is the work done by Haynes (1978), who conducted tensile tests with dumbbell-shaped saturated Fairbanks silt at temperatures of $-0.1,-1.7,-5.6,-9.4,-17.8,-34.4$, and $-56.7^{\circ} \mathrm{C}$ using “tension machine speeds” (i.e., loading rate) of $0.0423 \mathrm{~cm} / \mathrm{s}$ and $4.23 \mathrm{~cm} / \mathrm{s}$. He regressed these data and acquired two empirical formulas for each "tension machine speed.” Figure 1 shows the tensile strength of frozen silt in the temperature range of 0 to $-2{ }^{\circ} \mathrm{C}$ and at the "tension machine speed" of $0.0423 \mathrm{~cm} / \mathrm{s}$ (Haynes, 1978). This represents the only available empirical information of the tensile strength of frozen silt in the temperature range from 0 to $-2{ }^{\circ} \mathrm{C}$, and shows a steep increase in tensile strength just below $0{ }^{\circ} \mathrm{C}$.

\subsection{Tensile test apparatus}

A split-cylinder test is one alternative for determining the tensile strength of frozen soil. However, this method is not appropriate for ductile samples such as 
frozen soil close to the melting point of ice (Bragg and Andersland, 1980). In this experiment, the direct tensile test method was used. Jessberger (1980) presented typical shapes of specimens used for direct tensile test; we used that named “OFFENSEND” in this study (see Figure. 2). Tamrakar et al. (2005) confirmed the good performance of this shape in the study of the tensile strength of unfrozen soil. Therefore, we expected its good grip performance for our soft specimens. The apparatus used for this experiment is shown in Figure. 3.

\subsection{Test temperature}

The objective of this experiment was to observe the tensile strength of the frozen fringe. The temperature of the frozen fringe in frost susceptible clay and welded tuff was measured from 0 to $-0.8^{\circ} \mathrm{C}$ and at $-1.4^{\circ} \mathrm{C}$, respectively (Akagawa 1988, 1990; Akagawa et al. 1988). Based on these test results, a test temperature range of 0 to $-1.4{ }^{\circ} \mathrm{C}$ was adopted for this study. For comparison, the tensile strength at a positive temperature also was acquired. The temperatures at which tests were conducted were $+0.6,-0.15,-0.39,-0.49,-0.56,-0.64,-0.71,-0.79,-0.85$, and -1.31 ${ }^{\circ} \mathrm{C}$. The test temperature was monitored directly by thermocouples, which were placed in the specimen and calibrated to an accuracy of $\pm 0.02{ }^{\circ} \mathrm{C}$ with a standard temperature monitoring system. The specimen temperature was stabilized primarily by a walk-in cold room, which demonstrates a temperature fluctuation of $\pm 2{ }^{\circ} \mathrm{C}$ around the target temperature, and secondarily by an insulated box that was placed in the cold room and whose inner temperature was controlled with antifreeze liquid circulation as shown in Figure 4. A typical test temperature record is shown in Figure 5. 


\subsection{Soil used}

Our experiment was designed with two objectives in mind: (1) the mechanical properties of frozen soil, as discussed in this paper; and (2) the mechanism of frost heaving, which will be discussed in a future paper. This combination of objectives required special soil properties, including a high tensile strength. We used a diluvial silt named Dotan in Japan that has an average tensile strength of $750 \mathrm{kN} / \mathrm{m}^{2}$ in an undisturbed state. Table 1 contains a summary of Dotan's physical properties.

\subsection{Sample preparation}

The soil sample was dried and powdered. Then, it was mixed into a slurry with a water content twice of the liquid limit, de-aired by vacuum, and consolidated. The consolidated, trimmed soil sample is shown in Figure 6. The consolidation pressure was $50 \mathrm{kPa}$.

The trimmed sample was quickly frozen in a stainless steel container with liquid nitrogen in order to prevent the formation of ice lenses. The frozen sample was removed from the container and placed in the sample holder of the test apparatus shown in Figure 3. The test apparatus was kept in the cold room until the sample reached the target temperature (Figure 5).

\subsection{Loading speed}

Haynes (1975) and Zhu et al. (1985) studied the strain rate dependence of the tensile strength of frozen silts and reported that a lower strain rate (corresponding to ductile failure) affects the tensile strength, whereas the tensile strength is insensitive to a higher strain rate that corresponds to brittle failure at temperatures between -5 and $-10^{\circ} \mathrm{C}$. Since the test temperature range of this experiment is higher than that 
presented by Haynes et al. (1975) and Zhu and Carbee (1985)., we checked the dependence as shown in Figure. 7. Two stress-deformation curves are shown in the figure. The test temperatures were nearly identical at -0.16 and $-0.15^{\circ} C$, while the deformation speeds were 0.34 and $2.31 \mathrm{~mm} / \mathrm{min}$, respectively. The tensile strength under the lower deformation speed was about 30\% higher than that under the higher deformation speed. This is contrary to what is commonly accepted. It is not certain whether the test temperature difference of $0.01^{\circ} \mathrm{C}$ resulted in the $30 \%$ difference in tensile strength, assuming the strain rate does not influence the tensile strength.

Based on these results, the deformation speed is thought to be unimportant to the temperature-dependent tensile strength as long as the deformation speed is constant throughout the experiment. For this experiment, the deformation speed chosen was $2.31 \mathrm{~mm} / \mathrm{min}$.

\section{Test results}

\subsection{Stress-deformation curve}

Stress-deformation curves of unfrozen Dotan are shown in Figure 8. The two curves were acquired using deformation speeds of 0.88 and $0.34 \mathrm{~mm} / \mathrm{min}$, with resulting tensile strengths of 7.24 and $7.22 \mathrm{KN} / \mathrm{m}^{2}$, respectively. All of the stress-deformation curves of frozen Dotan are shown in Figure 9. The tensile strength of each test shown in Figure 8 and Figure 9 was calculated by dividing the maximum tensile force with each fracture area (see Table 2). The fracture mode of frozen Dotan, even in this narrow temperature range, seems to change from ductile 
to brittle with decreasing temperature. Examples of typical ductile and brittle fractured specimens are shown in Figure 10. However, there are two exceptional stress-deformation curves in Figure 9, i.e. -0.39 (a) and $-0.64{ }^{\circ} \mathrm{C}$. Their long high tensile strength plateaus are attributed to multiple fractures within these specimens, as shown in Figure 11. Fine, spider web-like strings were observed between the fractures, as shown in Figure 12, in the test conducted at the high temperature condition of $-0.15^{\circ} \mathrm{C}$ with a low deformation speed of $0.34 \mathrm{~mm} / \mathrm{min}$. These thin threads were present only for approximately several tens seconds. These are interpreted as elongated pore ice, disappearing quickly by sublimation.

\subsection{Tensile strength in frozen fringe temperature range}

The tensile strengths of frozen and unfrozen Dotan with respect to temperature are shown in Figure 13. The tensile strength of frozen Dotan is 20 to 70 times higher than that in the unfrozen state. The tensile strength at $+0.6{ }^{\circ} \mathrm{C}$ was 7.2 $\mathrm{kN} / \mathrm{m}^{2}$ (which is the mean value of two tests), whereas the tensile strength in the temperature range between -0.15 and $-1.31{ }^{\circ} \mathrm{C}$ vary between $164 \mathrm{kN} / \mathrm{m}^{2}$ and $498 \mathrm{kN} / \mathrm{m}^{2}$.

\section{Discussion}

As is shown in Figure 13, frozen soil demonstrates a high tensile strength even in the temperature range close to freezing, i.e., 0 to $-1.3^{\circ} \mathrm{C}$, as compared to that at a positive temperature. The obvious difference between positive and negative temperatures is the existence of pore ice in the frozen soil. In the following discussion, one structural model of frozen soil is proposed based on the empirical data to explain the development of steep and high tensile strength development in 
frozen fringe temperature range.

\subsection{Elements of tensile strength}

The high tensile strengths of frozen soil shown in Figure.13 can be attributed to some mechanical properties of frozen soil. It is assumed that the tensile strength obtained from direct tensile tests, $\sigma_{\mathrm{t}_{\text {Total }}}$, is composed of factors, such as:

$$
\sigma_{\mathrm{t}_{\text {Total }}}=\sigma_{\mathrm{t}_{\text {pore Ice }}}+\sigma_{\mathrm{t}_{\text {Soil Particle }}}+\sigma_{\mathrm{t}_{\text {other Factors }}}
$$

where, $\sigma_{\mathrm{t}_{\text {pore le }}}$ is the tensile strength derived from the pore ice network developed in a frozen soil, $\sigma_{\text {tsoil araicle }}$ is the tensile strength derived from the soil particle interaction at a positive temperature, and $\sigma_{\mathrm{t}_{\text {othe Facos }}}$ is the tensile strength derived from other unknown factors, such as adfreeze strength between particles and pore ice.

\subsection{Evaluation of $\sigma_{\mathrm{t}_{\text {por lee }}}$}

In order to evaluate $\sigma_{\mathrm{t}_{\text {pore lee }}}$, information on pore ice area in a unit section, $\mathrm{A}_{\text {Pore Ice' }}$, and the tensile strength of ice, $\sigma_{\text {Ice }}$ is required, since $\sigma_{\text {tpore ce }}$ may be calculated as:

$$
\sigma_{\mathrm{t}_{\text {Pore Ice }}}=\sigma_{\mathrm{t}_{\text {Ice }}} \bullet \mathrm{A}_{\text {Pore Ice }}
$$

In the following subsections, $\mathrm{A}_{\text {Pore Ice }}$ and $\sigma_{\mathrm{t}_{\mathrm{Ice}}}$ are defined using empirical data.

\subsubsection{Pore ice area in a unit section, $\mathrm{A}_{\text {Por Ice }}$}

Pore ice area in a unit section normal to the tensile stress, $A_{\text {Pore Ice }}$, can be calculated from the pore ice volume, $\mathrm{V}_{\text {Pore Ice }}$, in a unit volume of frozen soil, $\mathrm{V}_{\text {Total }}$, as follows:

$$
\mathrm{V}_{\text {Pore Ice }}(T)=\mathrm{V}_{\text {Pore Water }}-\mathrm{V}_{\text {Unfrozen Pore Water }}(T)
$$

where $V_{\text {Pore Water }}$ is the water volume in saturated Dotan at a positive temperature, $\mathrm{V}_{\text {Unfrozen Pore Water }}$ is the volumetric water content, and $\mathrm{T}$ is temperature in ${ }^{\circ} \mathrm{C}$. For this study, we acquired $V_{\text {Unfrozen Pore Water }}$ using the pulse nuclear magnetic resonance 
(NMR) method. Specimens were prepared as the same procedure shown in the section 2.4 except the freezing temperature (i.e., $-20{ }^{\circ} \mathrm{C}$ in this case). The pulse NMR apparatus was placed in a walk-in type cold room in which the temperature was maintained at $2{ }^{\circ} \mathrm{C}$. A simple 90 degree pulse was used to acquire the free induction decay (FID) curve. The FID curves for Dotan at various temperatures are shown in Figure 14. These curves consist of an FID component from pore ice and from unfrozen water:

$$
F I D_{\text {Total }}=F I D_{\text {Pore Ice }}+F I D_{\text {Unfrozen Water }}
$$

where,

$$
F I D_{\text {Pore Ice }}=A \exp \left(\frac{-t^{2}}{\alpha}\right)
$$

and

$F I D_{\text {Unfrozen Water }}=B \exp \left(\frac{-t}{\beta}\right)$

where, $\mathrm{t}$ is elapsed time and A, B, $\alpha, \beta$ are material constants. Generally, $F I D_{\text {Por lec }}$ has a short decay time in the range of tens of micro-seconds, whereas the decay time for $F I D_{\text {Unfrozen Water }}$ is much longer. The FID Unfroen Water can be differentiated from $F I D_{\text {Pore ce }}$ as a straight line in Figure 14, for the equation of $F I D_{\text {Unfrozen Water }}$ becomes a simple linear equation in a semi-log scale: $\log \left(F I D_{\text {Unfrozen Water }}\right)=\frac{-t}{\beta}+\gamma$, where $\gamma=\log B \cdot$ According to the decay properties of $F I D_{\text {Unfrozen Water }}$ and the data shown in Figure 14, the FID signal from liquid water in Dotan was determined to be the FID signal obtained at times later than $60 \mu$ s. 
A second approach was used in order to verify the $60 \mu$ s cutoff. This approach is based on the principle that the intensity of $F I D_{\text {Unfrozen Water }}$ is proportional to the water content (Tice et al. 1982):

$$
\begin{aligned}
\left(\frac{\mathrm{FID}_{\text {Pore Water }}(10)}{W}\right) & =\left(\frac{\mathrm{FID}_{\text {Unfrozen Water }}(T)}{W_{\mathrm{u}}(T)}\right) \\
& =\text { Const. }
\end{aligned}
$$

Where $\mathrm{FID}_{\text {Pore Water }}(10)$ is FID signal intensity of pore water at $10^{\circ} \mathrm{C}$, T is the temperature of the frozen sample in ${ }^{\circ} \mathrm{C}, w$ is gravimetric water content of the specimen at $10^{\circ} \mathrm{C}$, and $w_{u}$ is gravimetric unfrozen water content of the specimen at the temperature $\mathrm{T}^{\circ} \mathrm{C}$. The ratio of the signal intensity from each temperature over the FID obtained at 10 ${ }^{\circ} \mathrm{C}$, i.e. Y in Equation 6, should be constant in the time period when the signal from unfrozen water, $F I D_{\text {Unfrozen Water }}$, is predominant, for:

$$
\begin{aligned}
Y & =\frac{\mathrm{FID}_{\text {Unfrozen Water }}(T)}{\mathrm{FID}_{\text {Pore Water }}(10)} \\
& =\frac{W_{\mathrm{u}}(T)}{w} \\
& =\text { Const. }
\end{aligned}
$$

The results of this analysis are shown in Figure 15. Equation 6 requires the ratio of

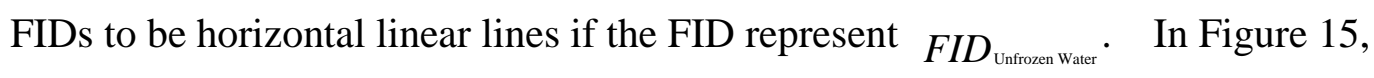
the early portion of the FID curves at times less than $60 / \mathcal{S}$ are not linear, whereas the FID signals at times greater than $60 / \mathcal{S}$ satisfy Equation 6. Therefore, $60 / \boldsymbol{S}$ is 
confirmed as the suitable timing to read the signal intensity of ${ }_{F I D_{\text {Unfrozen Water }}}$ for Dotan.

Using this approach, the FID intensities at different temperatures were used to calculate the gravimetric unfrozen water content of Dotan as shown in Figure. 16, following the method defined by Tice et al. (1982). Figure 16 illustrates a temperature-dependent unfrozen water content typical of clayey soil.

In order to calculate pore ice volume, the temperature-dependent unfrozen water content was regressed as (Anderson et al., 1973):

$$
W_{U_{\text {Regressed }}}(T)=12.979(|T|)^{-0.3557}
$$

where, $0>T$.

The gravimetric unfrozen water content was converted to the volumetric unfrozen water content, $V_{u}$, as:

$$
\begin{aligned}
V_{u}(T) & =\frac{V_{\mathrm{s}} \mathrm{G}_{\mathrm{s}}}{\mathrm{G}_{\mathrm{W}}} W_{U_{\text {Regersed }}}(T) \\
& =1.17 W_{U_{\text {Regresed }}}(T)
\end{aligned}
$$

where $V_{s}$ is volumetric soil particle content, $G_{\mathrm{s}}$ and $G_{\mathrm{W}}$ are specific gravities of the soil particles and of water, respectively. Finally, the volumetric pore ice content was calculated as:

$$
V_{i}(T)=V_{u}(0)-V_{u}(T)
$$

where $V_{u}(0)=0.568$ which is the volumetric water content of the specimen used for unfrozen water content measurement with NMR. The volumetric unfrozen water content and ice content with respect to temperature are shown in Figure17. 


\subsubsection{Tensile strength of networked pore ice}

(1) Tensile strength of ice, $\sigma_{t_{i c e}}$

Research on the mechanical properties of ice has a long history. However, information on the tensile strength of ice at the high temperatures in the frozen fringe is not readily available (Sinha 1985). Moreover, there is almost no direct information describing the crystal structure and size of pore ice in frost susceptible soil within the frozen fringe. For this analysis, data from one old but reliable ice tensile strength test (Kubo 1941) is used (see Figure 18). These data were regressed as:

$$
\sigma_{t_{\text {ice }}}=-0.218 T^{2}-35.9 T+686
$$

where $\sigma_{t_{\text {ice }}}$ is in $\mathrm{kN} / \mathrm{m}^{2}$.

(2) Pore ice area in unit section, $A_{\text {Pore Ice }}$

As shown in Figure 13, frozen Dotan demonstrates a considerably high tensile strength in the frozen fringe temperature range. Additionally, frozen Dotan contains a considerable amount of pore ice, as shown in Figure 17. Therefore, the high tensile strength of frozen Dotan may be attributed, in part, to the pore ice.

In order to simplify the micro structure of frozen Dotan, an individual soil particle is assumed to have a cubic shape and to be surrounded with thin unfrozen water films and pore ice as shown in Figure 19(a). The pore ice exists as the lattice shown as black squares in Figure 19(b). In this idealized structural model, the pore ice area in unit section, $A_{\text {Pore ce }}$,is calculated as follows, assuming a three dimensional array of cubes with the array direction agreeing with the tensile stress: 


$$
\mathrm{A}_{\text {Pore Ice }}=L_{i}{ }^{2}-L_{u}{ }^{2}
$$

where, $L_{i}$ is the length of the unit cube edge, $L_{u}$ is the length of unfrozen water and the pore ice boundary shown in Figure 19(a), and

$$
L_{U}=\sqrt[3]{V_{S}+V_{U}}
$$

Finally, substituting Equation(10), (11) and (12) for Equation(2), the tensile strength of pore ice in this model is calculated as:

$$
\sigma_{\text {tpor lee }_{\text {f }}}=\left(-0.218 T^{2}-35.9 T+686\right)\left(L_{i}{ }^{2}-L_{u}{ }^{2}\right)
$$

The calculated results using Equation 13, along with the experimental data presented in Figure 13, are shown in Figure 20. The maximum pore ice tensile strength calculated using Equation 10 is also shown in the figure.

The calculated pore ice tensile strength is nearly one-half of the observed frozen soil tensile strength. Therefore, the tensile strength of the pore ice in a frost susceptible soil within the frozen fringe temperature range may carry the half of $\sigma_{\mathrm{t}_{\text {true }}}$. However, this conclusion may not be highly reliable, for it was derived from empirical data, and simplifications such as $\sigma_{t_{i c e}}$ A $A_{\text {por lee }}$, and the proposed structural model. These items will need to be clarified empirically with future research.

\subsection{Tensile strength of soil particle $\sigma_{\text {tosilnainic }}$}

Unfortunately, no experimental approach has been developed for evaluating the tensile strength of the soil particle framework in a frozen soil. For this analysis, we assumed that the tensile strength of soil framework is equivalent to the tensile strength of unfrozen Dotan, which was measured as $7 \mathrm{kN} / \mathrm{m}^{2}$. Since this value is so 
small, we may ignore this factor.

\subsection{Tensile strength derived by other elements $\sigma_{\mathrm{t}_{\text {other factos }}}$}

Since $\sigma_{\mathrm{t}_{\text {por le }}}$ discussed in Section 4.2 explains only about half of the tensile strength observed, other factors must contribute to the high tensile strength of warm frozen soil, e.g., the interaction between soil particles and pore ice. Future research may be able to define these "other factors" and their contribution to the tensile strength.

\subsection{Predominant element of tensile strength}

The tensile strength of pore ice was found to be about half of $\sigma_{t_{\text {Toal }}}$. The reliability of this value depends on the accuracy of $\sigma_{t_{\text {ice }}}$ and $\mathrm{A}_{\text {Pore Ice }}$, which were calculated in this study. Unless the mechanical properties of pore ice are different from conventional ice, this analysis indicates that $\sigma_{t_{i c e}}$ will be the predominant factor of $\sigma_{t_{\text {Toual }}}$.

\subsection{Deduced pore ice framework}

The model framework of pore ice shown in Figure 19 differs from that proposed by Miller (1978). However, both models are similar in that the pore ice forms a framework in a frozen soil. Only direct observation of the framework will finalize the discussion of its shape. Until then, the pore ice framework model shown in Figure 19 is a reasonable representation for this analysis.

One noteworthy point is that Miller's model, which incorporates regelation as a key element of the ice lens segregation mechanism, did not address fracturing within the pore ice framework during ice lens initiation. However, if the ice pressure in the frozen fringe, which can be defined by the Generalized 
Clausius-Clapeyron Equation, becomes greater than the tensile strength identified in this study, the frozen fringe may fracture, eliminating the need for regelation.

\section{Conclusions}

The tensile strength of frost susceptible frozen soil in the frozen fringe temperature range, i.e. 0 to $-2{ }^{\circ} \mathrm{C}$, was measured experimentally. From these measurements, we conclude:

1) frozen soil in the frozen fringe temperature range has a remarkably high tensile strength compared to unfrozen soil;

2) the tensile strength may be derived from the pore ice framework;

3) the pore ice framework may be represented as a cubic array, as presented in this paper; and

4) the pore ice framework must be ruptured in order for an ice lens to initiate.

\section{Acknowledgment}

Authors would like to express our appreciation to Dr. S. B. Tamrakar for kindly furnishing his newly developed tensile test apparatus to us.

Authors are much indebted to Dr. M.M.Darrow of UAF for her useful advice in preparing this manuscript. 


\section{Reference}

Akagawa, S., 1988: Experimental study of frozen fringe characteristics. Cold Regions Science and Technology, 15: 209-223.

Akagawa, S., 1990: X-ray Photography Method for Experimental Studies of the Frozen Fringe Characteristics of Freezing Soil. U.S.A. Cold Regions Research and Engineering Laboratory, CRREL Special Report, 90-5: 1-69

Akagawa, S., Goto, S. and Saito, A., 1988: Segregation freezing observed in welded tuff by open system frost heave test. Proceedings of Fifth International Conference on Permafrost, Trondheim, Norway: 1030-1035.

Anderson, D. M., Tice, A.R. and McKim, H.L., 1973: The Unfrozen Water and The Apparent Specific Heat Capacity of Frozen Soils. Proceedings of Second International Conference on Permafrost, Yakutsk, U.S.S.R.: 289-295.

Beskow, G., 1935: Soil freezing and frost heaving with special application to roads and railroads. The Swedich Geological Society, Series C, 375(26th year book), 14-21. Translations by O.J. Osterberg, 1947. or Black, P. and Hardenberg, M.J., 1991: Historical perspectives in frost heave research : The early works of S. Taber and G. Beskow. U.S.A. Cold Regions Research and Engineering Laboratory, CRREL Special Report 91-23.

Black P.B., Hardenberg M.J., 1991. Historical perspectives in frost heave research, CRREL Special Report, vol. 91-23.U.S.A. Cold Regions Research and Engineering Laboratory, pp.3-7.

Bragg, R.A., and Andersland, O.B., 1980: Strain Rate, Temperature , and Sample Size Effects on Compression and Tensile Properties of Frozen Sand. Proceedings of the 
second International Symposium on Ground Freezing, Trondheim, Norway, pp.34-47.

Gilpin,R.R., 1979: A model of the "Liquid-Like" layer between ice and a substrate with applications to wire regelation and particle migration. Journal of Colloid and Interface Science, 68, 2: 235-251.

Gilpin R.R., 1980: A model for the prediction of ice lensing and frost heave in soils. Water Resources Research, 16, 5: 918-930.

Haynes, F.D., Karalius, J.A. and Kalafut, J., 1975: Strain Rate Effect on the Strength of Frozen Silt, USA Cold Regions Research and Engineering Laboratory, CRREL Research Report 350.

Haynes, F.D., 1978: Strength and Deformation of Frozen Silt. Proceedings of the Third International Conference on Permafrost, Edmonton, Alberta, Canada, 1, pp.655-661.

Jessberger, H.L., 1980: STATE-OF-THE-ART-REPORT, GROUND FREEZING: MECHANICAL PROPERTIES, PROCESSES AND DESIGN. Proceedings of the Second International Symposium on Ground Freezing, Trondheim, Norway, pp,1-33.

Kubo, Y., 1941: Construction Bureau, South Mancyurian Railway Company Study on River Ice(In Japanese). or USA CRREL, Translation T50, (1955).

Lade, P.V., Jessberger, H.L. and Diekmann, N., 1980: Stress-strain and Volumetric behavior of frozen soils. Second International Symposium on Ground Freezing, Trontheim, Norway, pp.48-64.

Miller, R.D., 1978: Frost heaving in non-colloidal soils. Proceedings of the thired 
International Conference on Permafrost, Edmonton, Canada, pp.708-713.

Sinha, N.K., 1983, Dose the Strength of Ice Depend on Grain Size at High Temperatures?. Scripta Metallurgica, 17: 1269-1273.

Takagi,S., 1980: The adsorption force theory of frost heaving. Cold Regions Science and Technology, 3: 57-81.

Tamrakar, S. B., Toyosawa, Y., Mitachi T. and Itoh, K., 2005: Tensile Strength of Compacted and Saturated Soils using Newly Developed Tensile Strength Measuring Apparatus, Soils and Foundations, 45, 6: 103-109.

Taber,S., 1929: Frost heaving, Journal of Geology, 37: 428-461.

Tice, A.R., Oliphant, J.L., Nakano, Y. and Jenkins, T.F., 1982: Relationship between the Ice and Unfrozen Water Phase in Frozen Soil as Determined by Pulsed Nuclear Magnetic Resonance and Physical Desorption Data. USA Cold Regions Research and Engineering Laboratory, CRREL Report 82-15.

Vialov, S.S., Gmoshinskii, S.E., Gorodetskii, V.G., Grigoriva, V.G., Zaretskii, Iu.K., Pekarskaia, N.K., and Shusherina, E.P., 1965: The Strength and Creep of Frozen Soil and Calculations for Ice-soil Relating Structure (Prochnost'I Polzuchest' Merzlukh Gruntov I Raschety Ledogruntovykh ograzhdenii),USA Cold Regions Research and Engineering Laboratory, CRREL Translation 76, pp.1-301.

Zhu, Y. and Carbee, D.L., 1985: Strain Rate Effect on the Tensile Strength of Frozen Silt. Proceedings of the Fourth International Symposium on Ground Freezing, Sapporo, Japan, pp.153-157. 


\section{Tables}

\begin{tabular}{|c|c|c|}
\hline \multicolumn{2}{|c|}{ Specific Gravity of soil particle [ - ] } & 2.70 \\
\hline \multicolumn{2}{|c|}{ Liquid Limit $\quad$ WL [\%] } & 62.3 \\
\hline \multicolumn{2}{|c|}{ Plastic Limit WP [\%] } & 41.9 \\
\hline \multicolumn{2}{|c|}{ Plasticity Index IP [\%] } & 20.4 \\
\hline \multicolumn{2}{|c|}{ Water Content w [\%] } & 48.74 \\
\hline \multicolumn{2}{|c|}{ Wet Density $[\mathrm{g} / \mathrm{cm} 3]$} & 1.73 \\
\hline \multirow{4}{*}{ 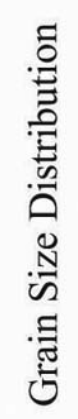 } & Gravel $z \quad 75$ mm [\%] & 0 \\
\hline & Sand $0.075-2 \mathrm{~mm}[\%]$ & 24 \\
\hline & Silt $0.005-0.075 \mathrm{~mm}[\%]$ & 48 \\
\hline & Clay $>0.005 \mathrm{~mm}[\%]$ & 28 \\
\hline
\end{tabular}

Table 1 Soil properties of Dotan 


\begin{tabular}{ccccc}
\hline Test Number & Temperature $\left({ }^{\circ} \mathrm{C}\right)$ & Section Area $\left(\mathrm{cm}^{2}\right)$ & Deformation Speed $(\mathrm{mm} / \mathrm{min})$ & Maximum Tensile Strength $\left(\mathrm{kN} / \mathrm{m}^{2}\right)$ \\
\hline \hline 1 & 0.6 & 15 & 0.34 & 7.22 \\
2 & 0.6 & 15 & 0.88 & 7.23 \\
3 & -0.15 & 6.44 & 2.31 & 417 \\
4 & -0.39 & 3.57 & 2.31 & 257 \\
5 & -0.39 & 5.10 & 2.31 & 453 \\
6 & -0.49 & 5.84 & 2.31 & 302 \\
7 & -0.56 & 4.64 & 2.31 & 439 \\
8 & -0.64 & 4.58 & 2.31 & 363 \\
9 & -0.71 & 5.13 & 2.31 & 459 \\
10 & -0.79 & 3.86 & 2.31 & 340 \\
11 & -0.79 & 5.07 & 2.31 & 499 \\
12 & -0.85 & 2.54 & 2.31 & 432 \\
13 & -1.31 & 2.10 & 2.31 & 212 \\
14 & -0.16 & 6.95 & 0.34 & 511 \\
15 & -0.38 & 6.62 & 1.65 & \\
\hline
\end{tabular}

Table 2 Tensile test results 
9. Figures

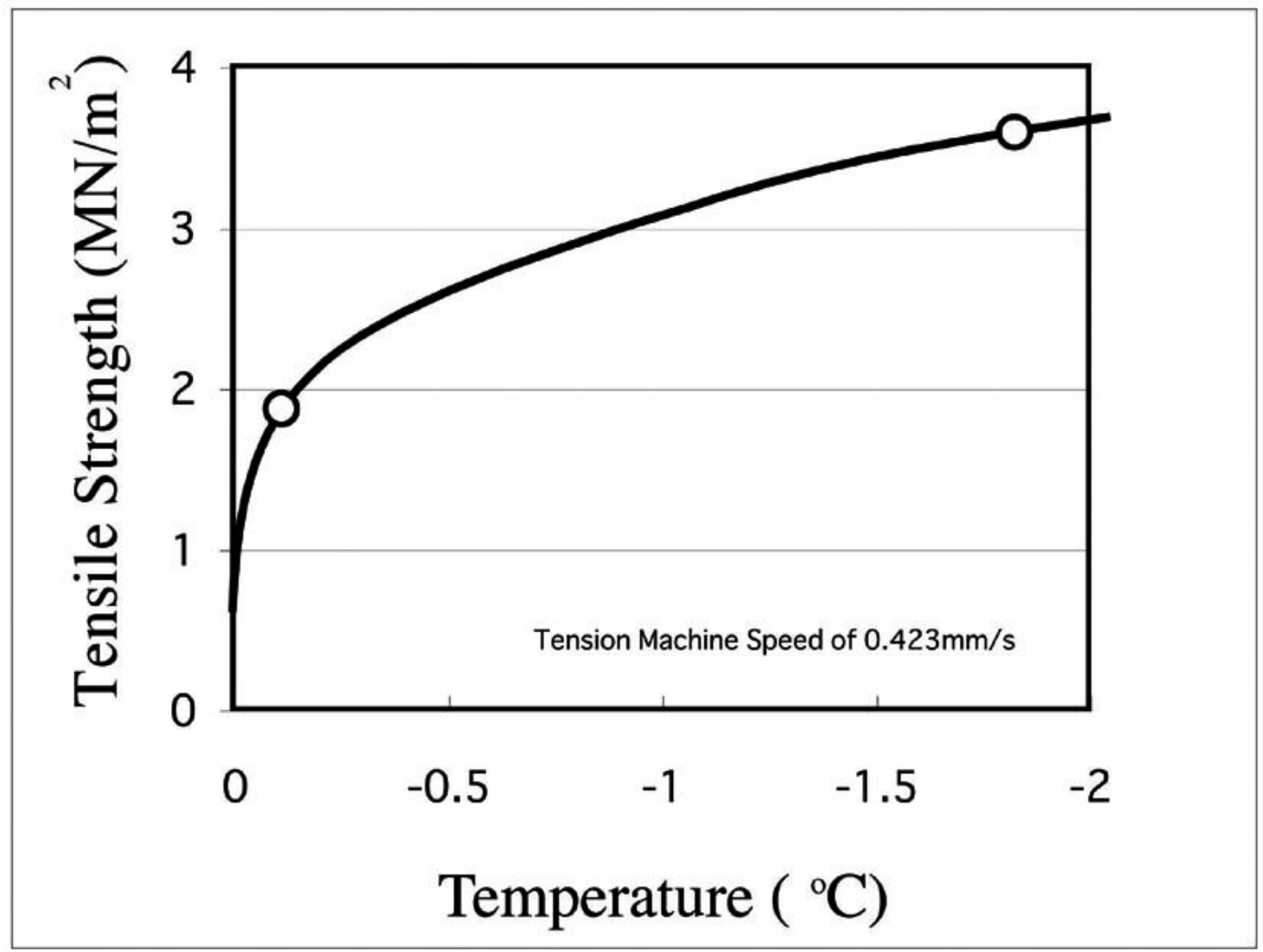

Figure 1 Tensile strength of frozen Fairbanks silt (adapted from Haynes 1978) 


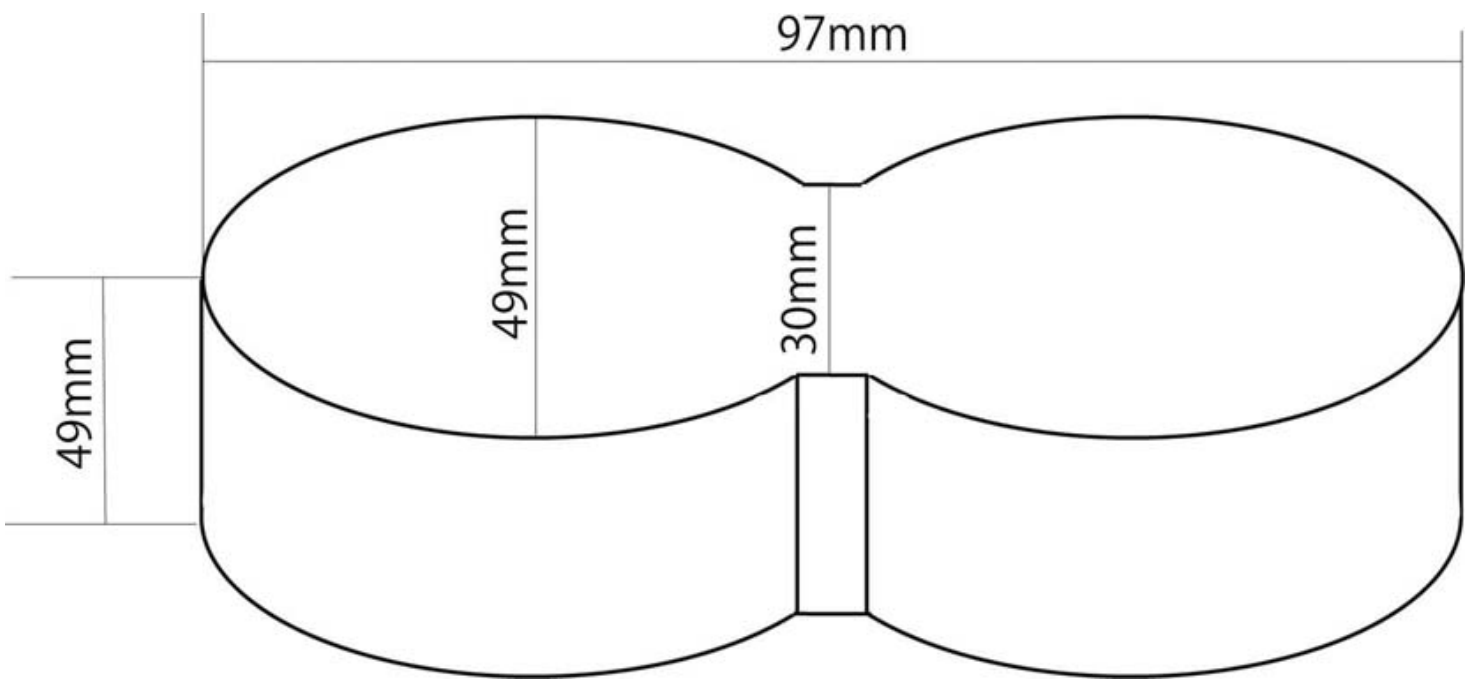

Figure 2 Schematic drawing of specimen 


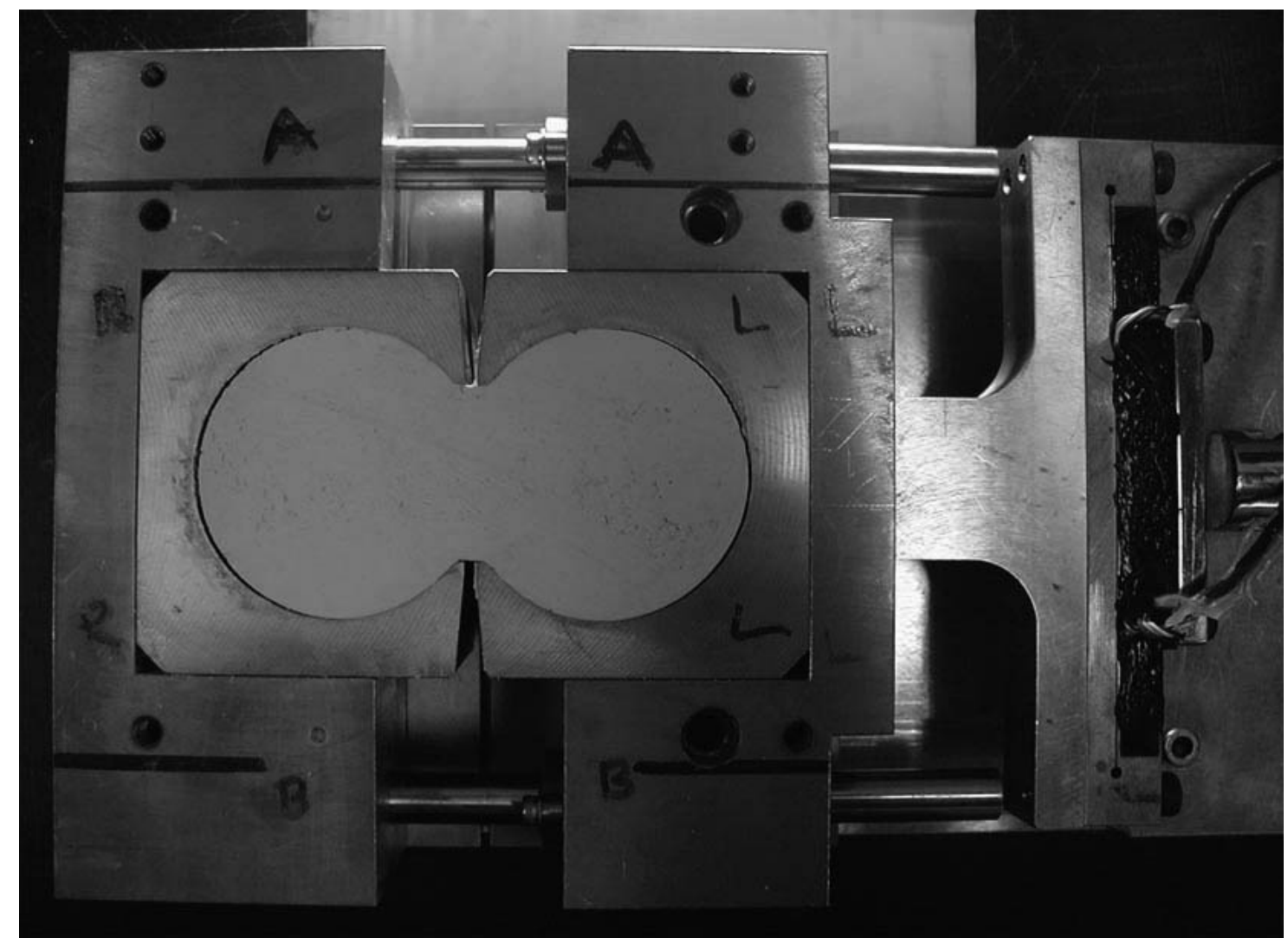

Figure 3 Photo of test apparatus (Tamrakar et.al., 2005) 


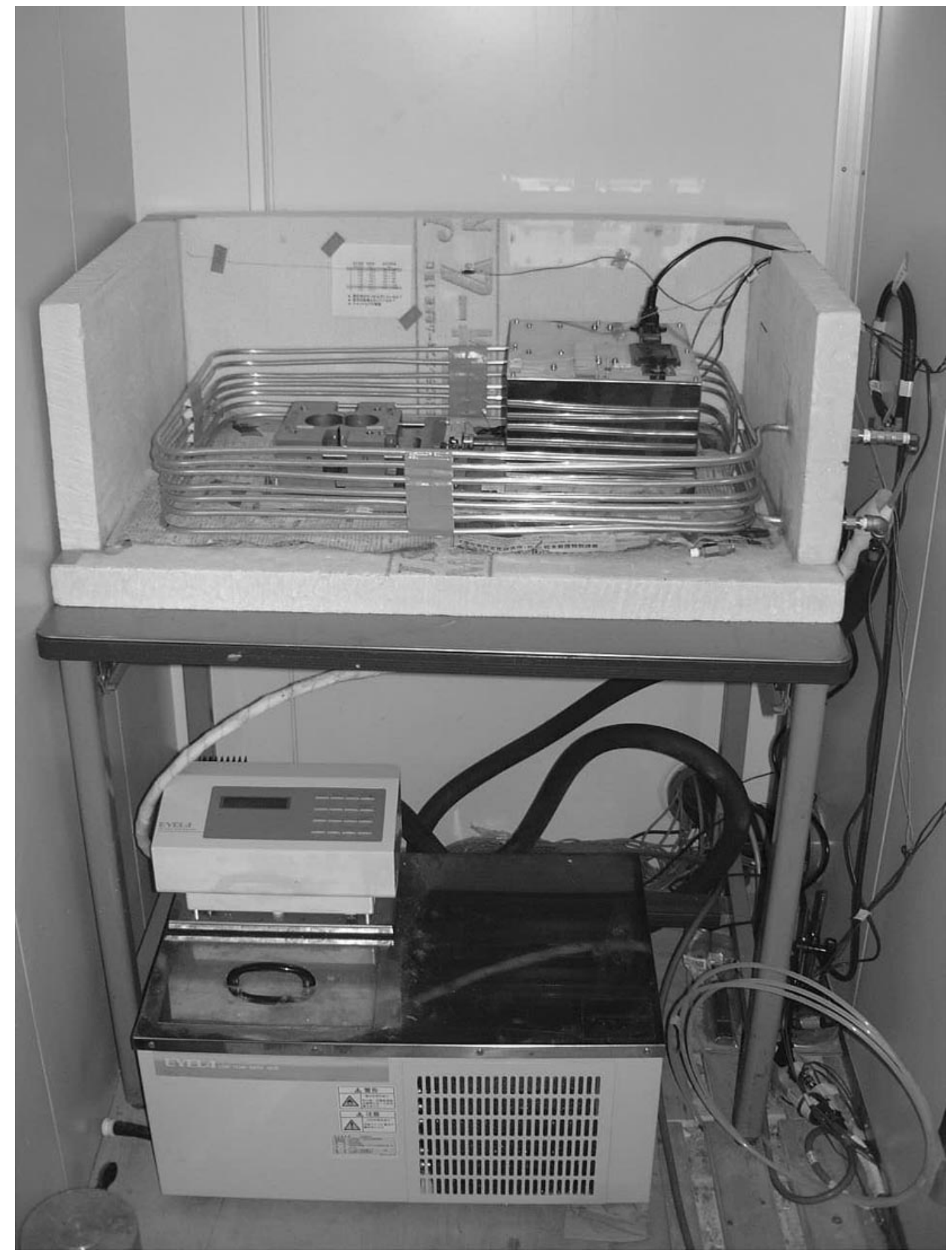

Figure 4 Complete view of test apparatus, including the surrounding insulation box 


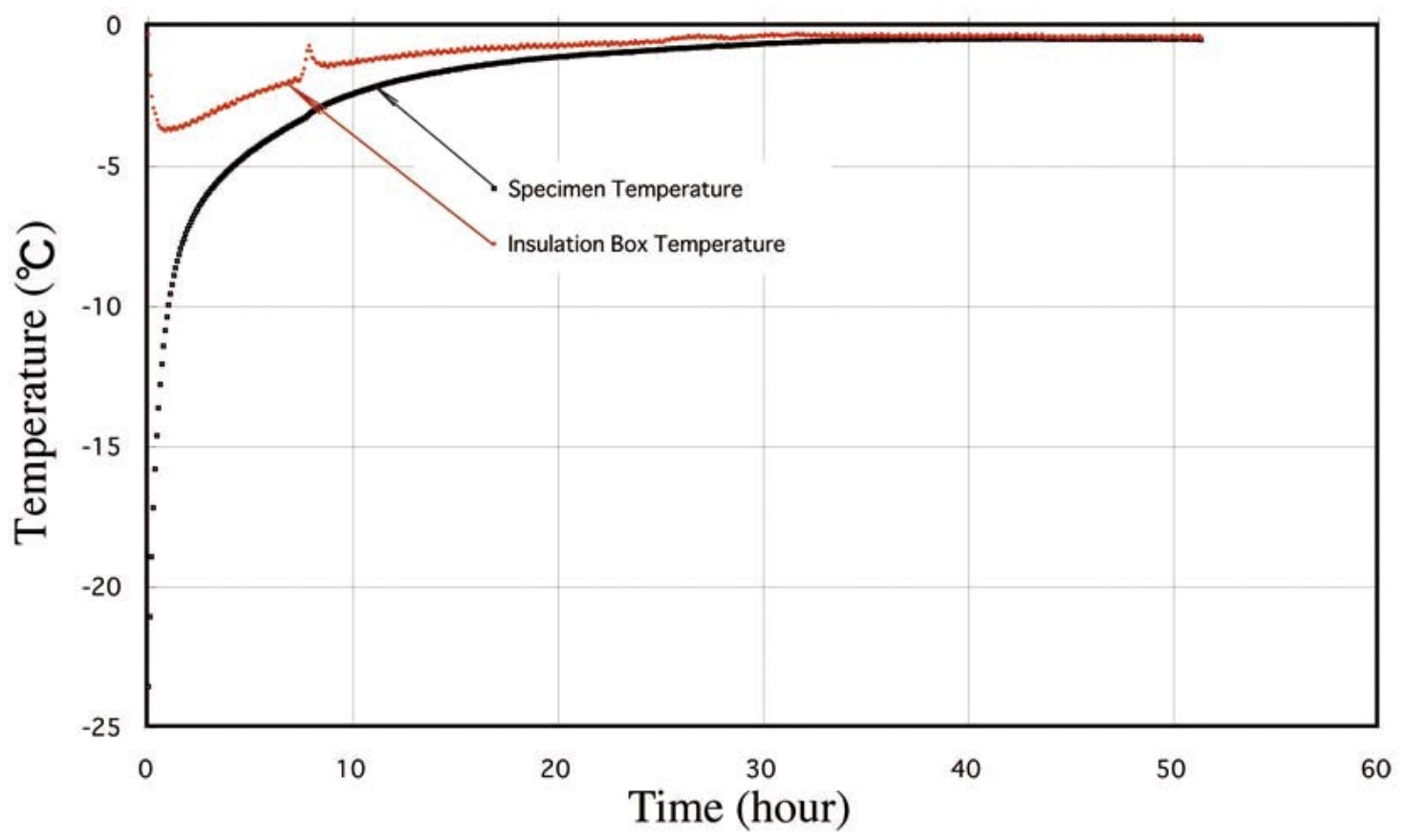

Figure 5 Typical temperature stabilization of the test specimen 


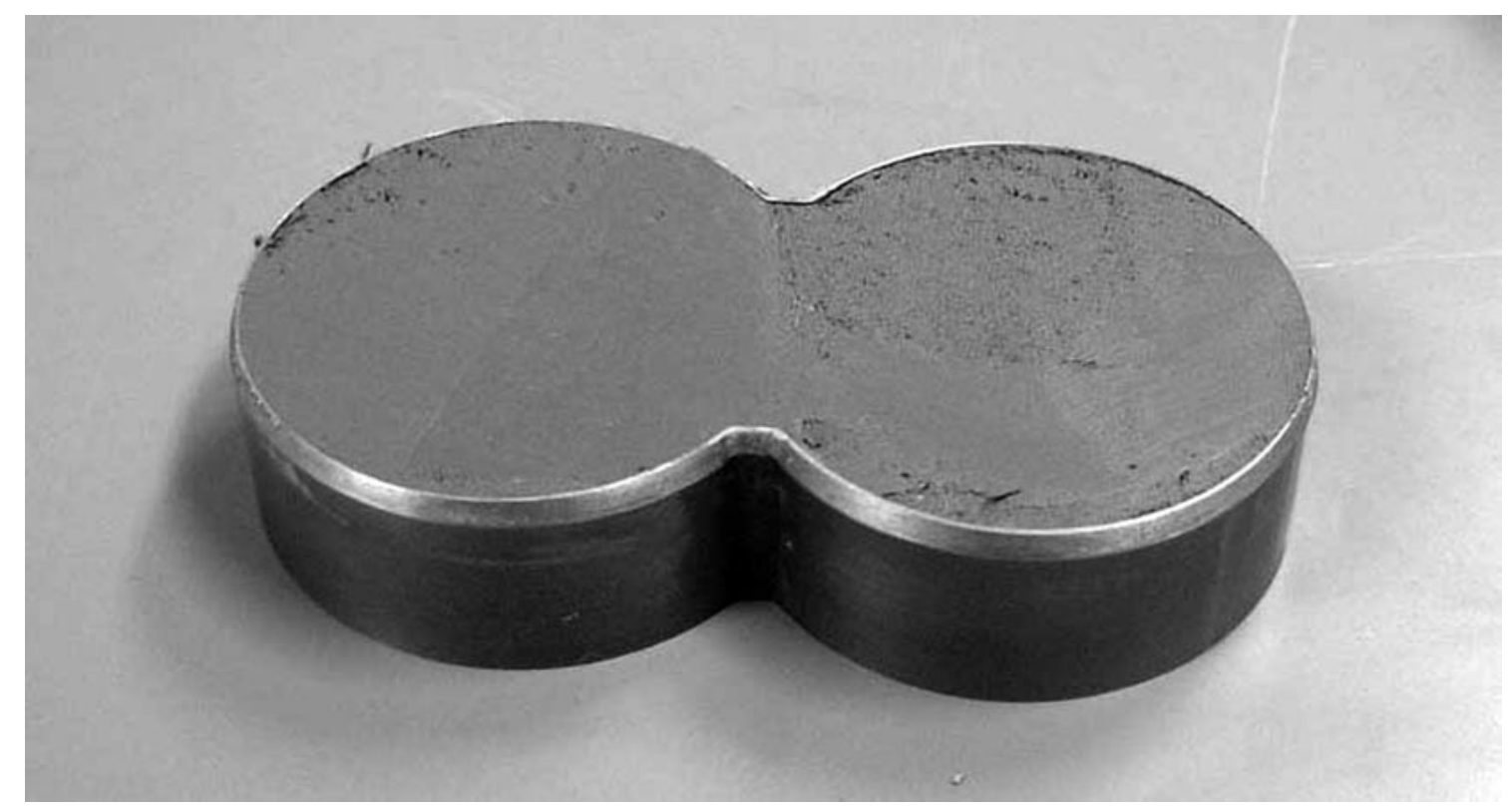

Figure 6 consolidated and trimmed sample prior to testing 


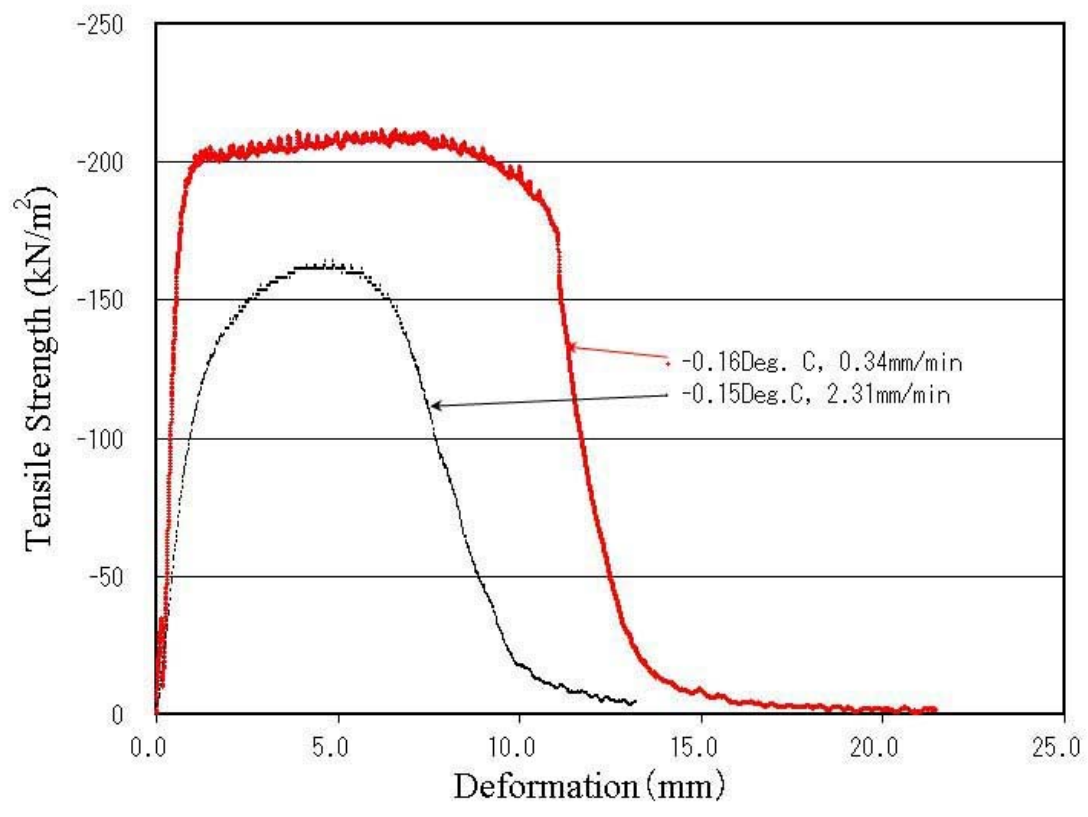

Figure 7 Strain rate influence on tensile strength 


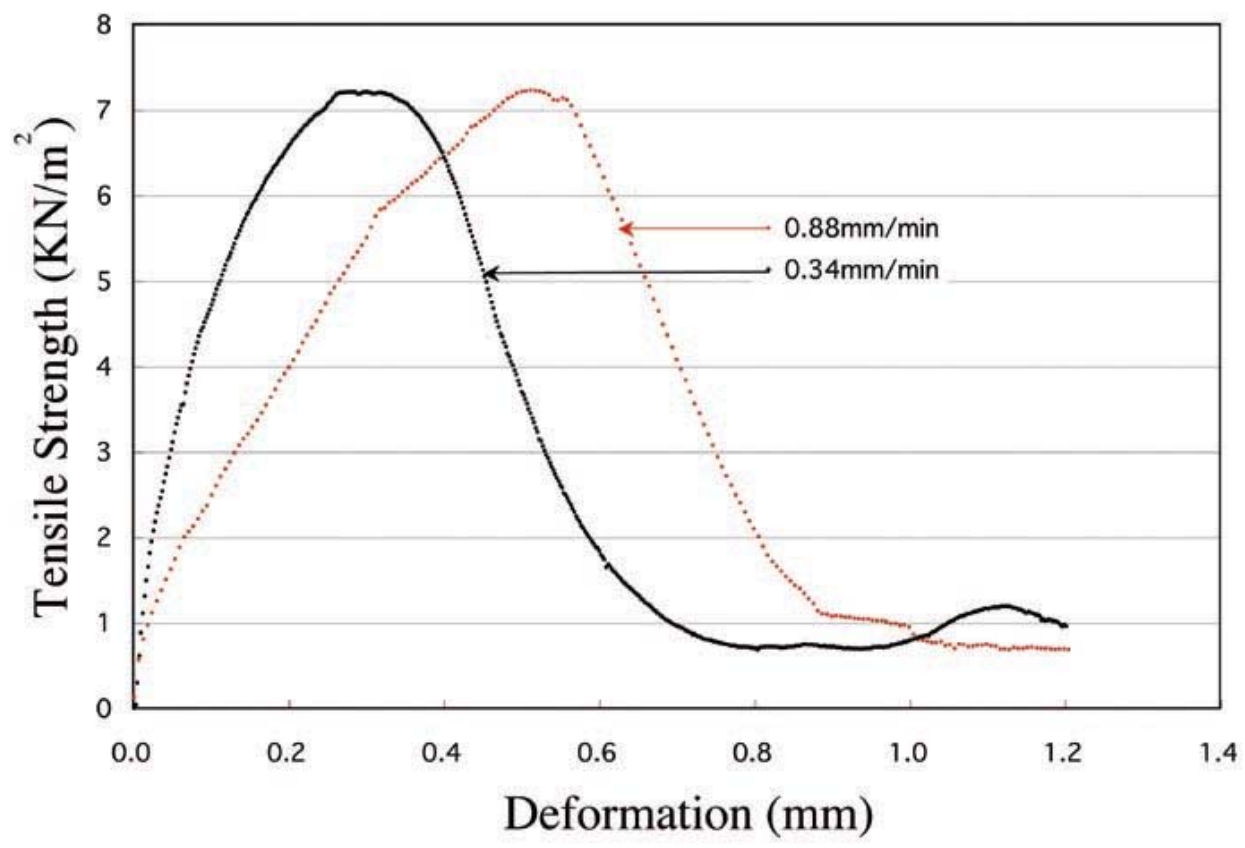

Figure 8 Stress-deformation curves of unfrozen Dotan 


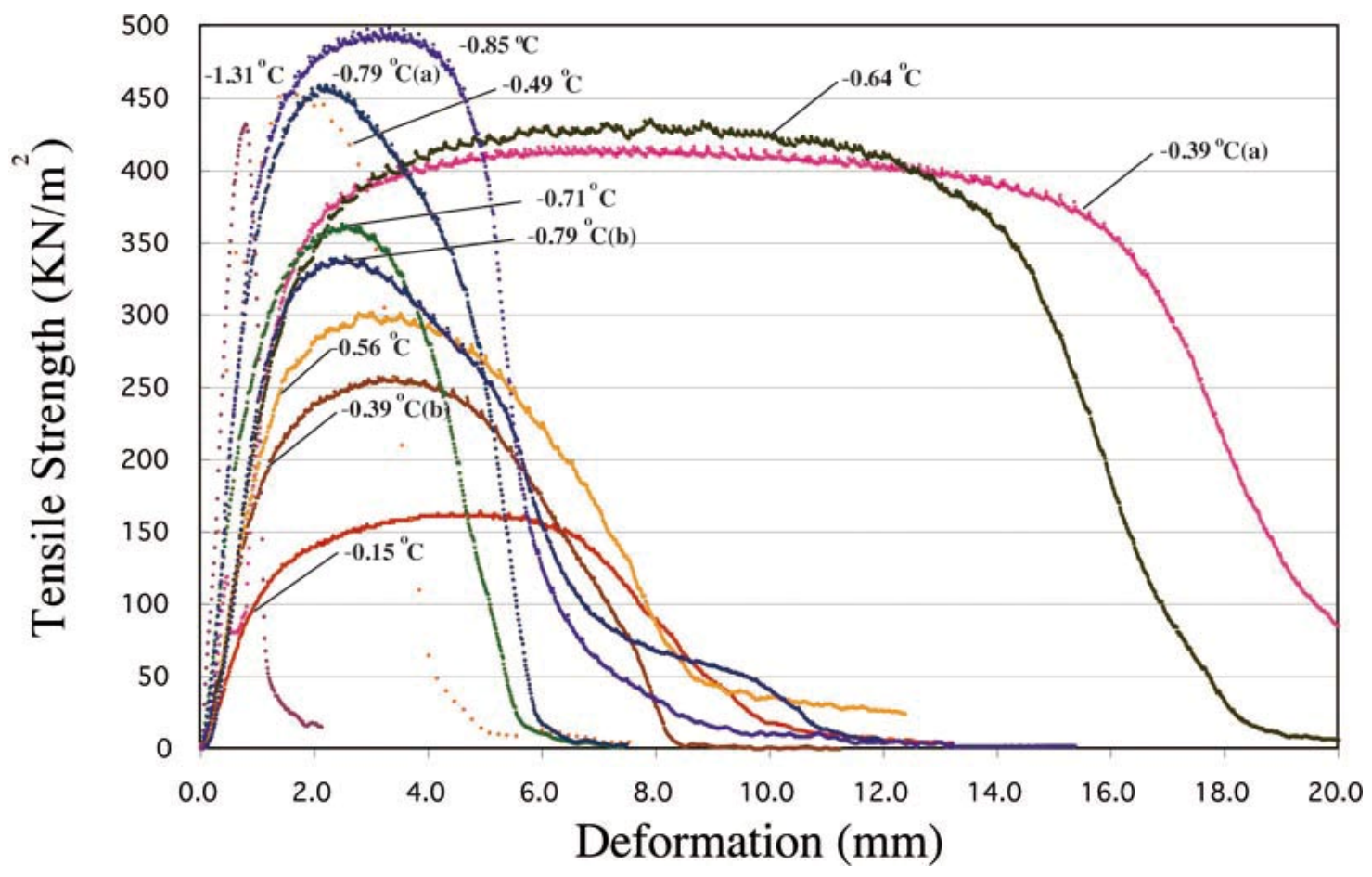

Figure 9 Stress-deformation curves of frozen Dotan 


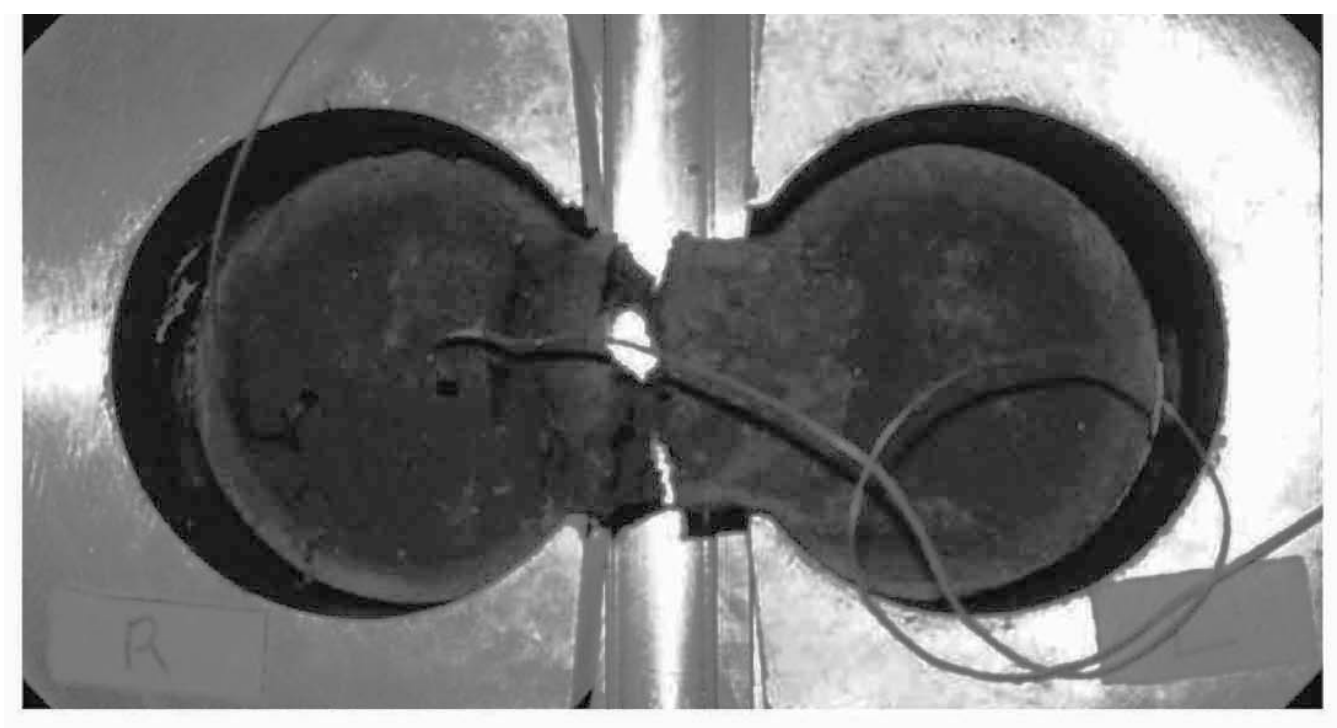

a) fractured specimen $\left(-0.15^{\circ} \mathrm{C}\right.$, Test number 3 in Table 2) (Ductile)

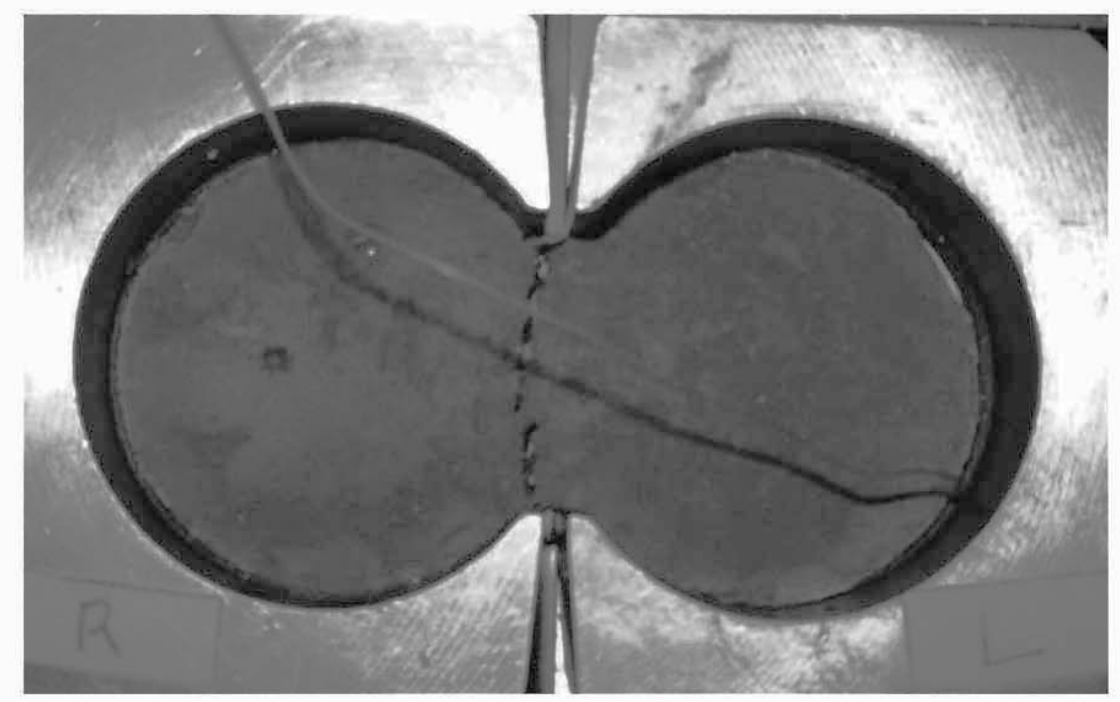

b) fractured specimen $\left(-1.31^{\circ} \mathrm{C}\right.$, Test number 13 in Table 2) (Brittle)

Figure 10 Typical fractured specimen 


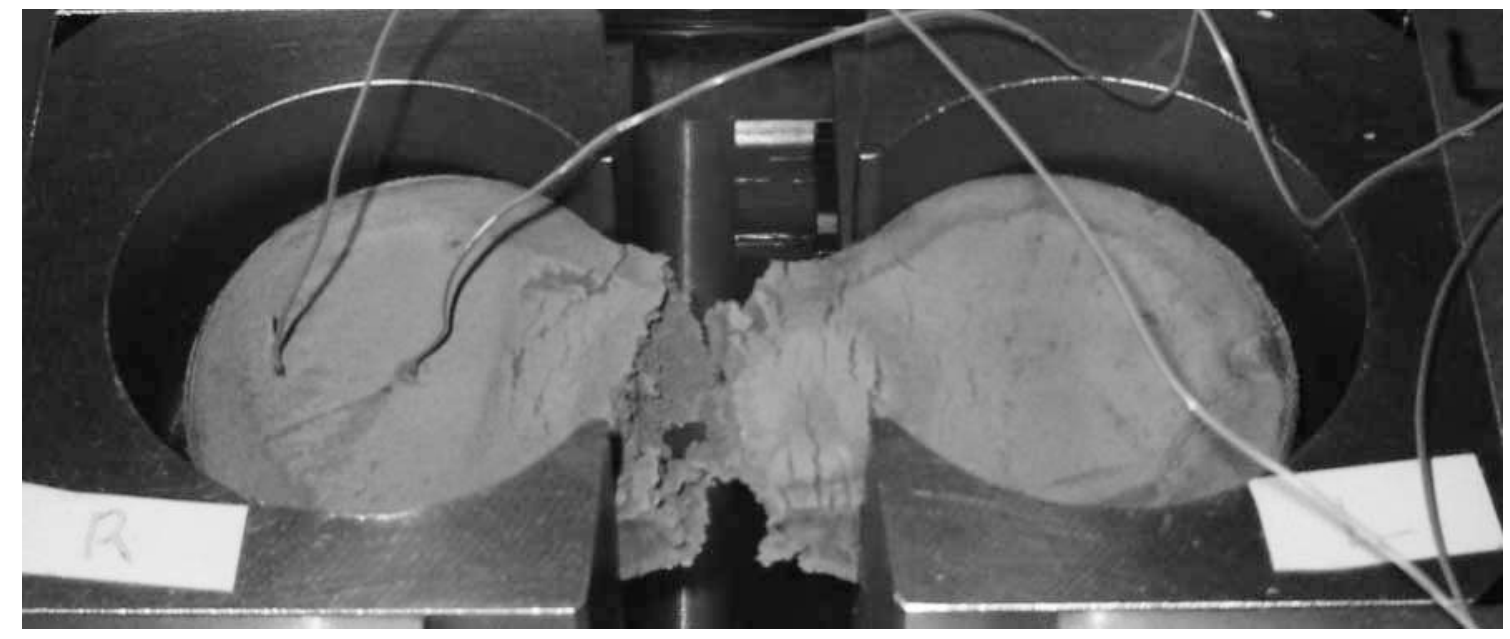

Figure 11 Fractured specimen with plural fractures (Test number 4 in Table 2) 


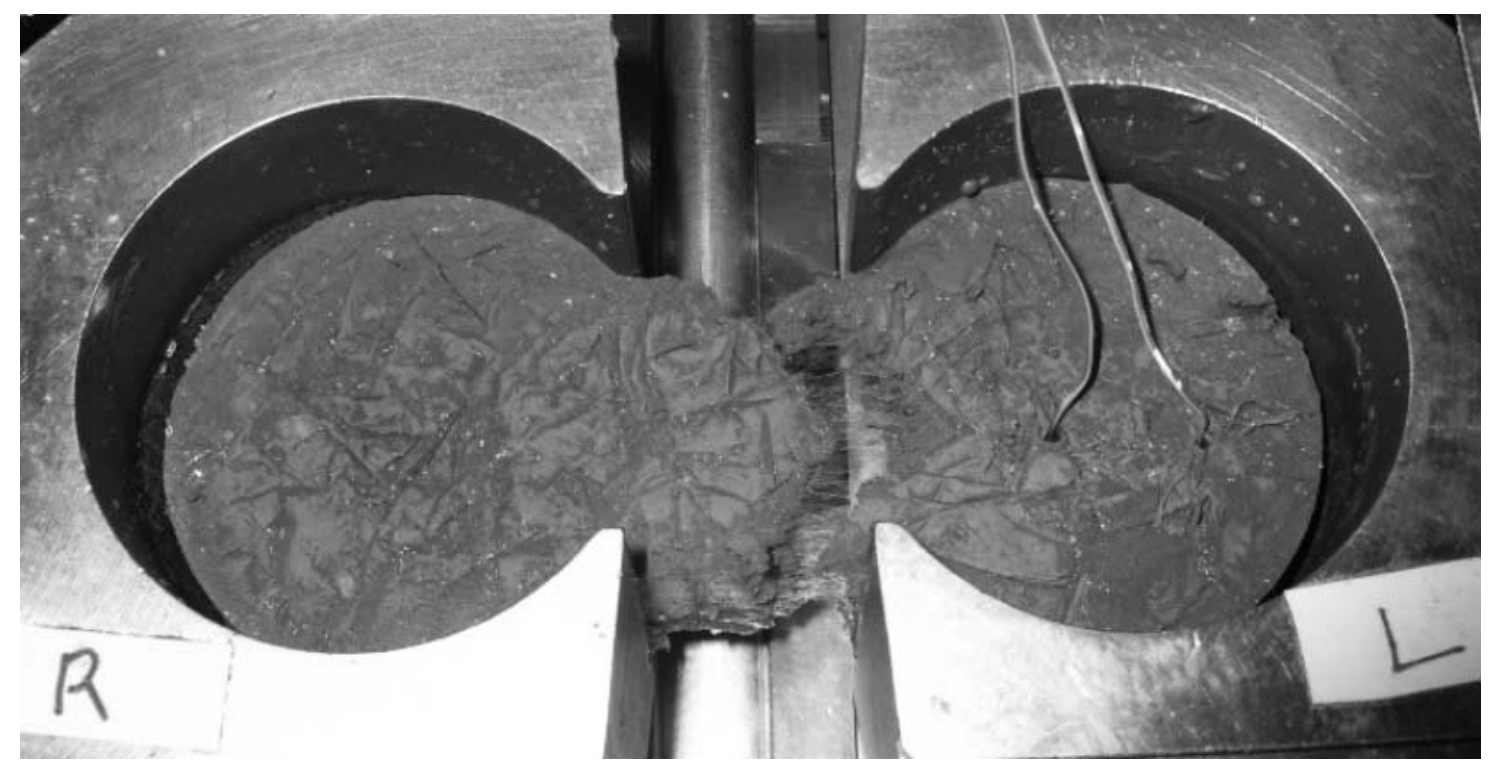

Figure12 Observed fine spider web-like-strings prior to sublimation at test condition of $-0.15{ }^{\circ} \mathrm{C}$ and $0.34 \mathrm{~mm} / \mathrm{min}$ (Test number 14 in Table 2$)$ 


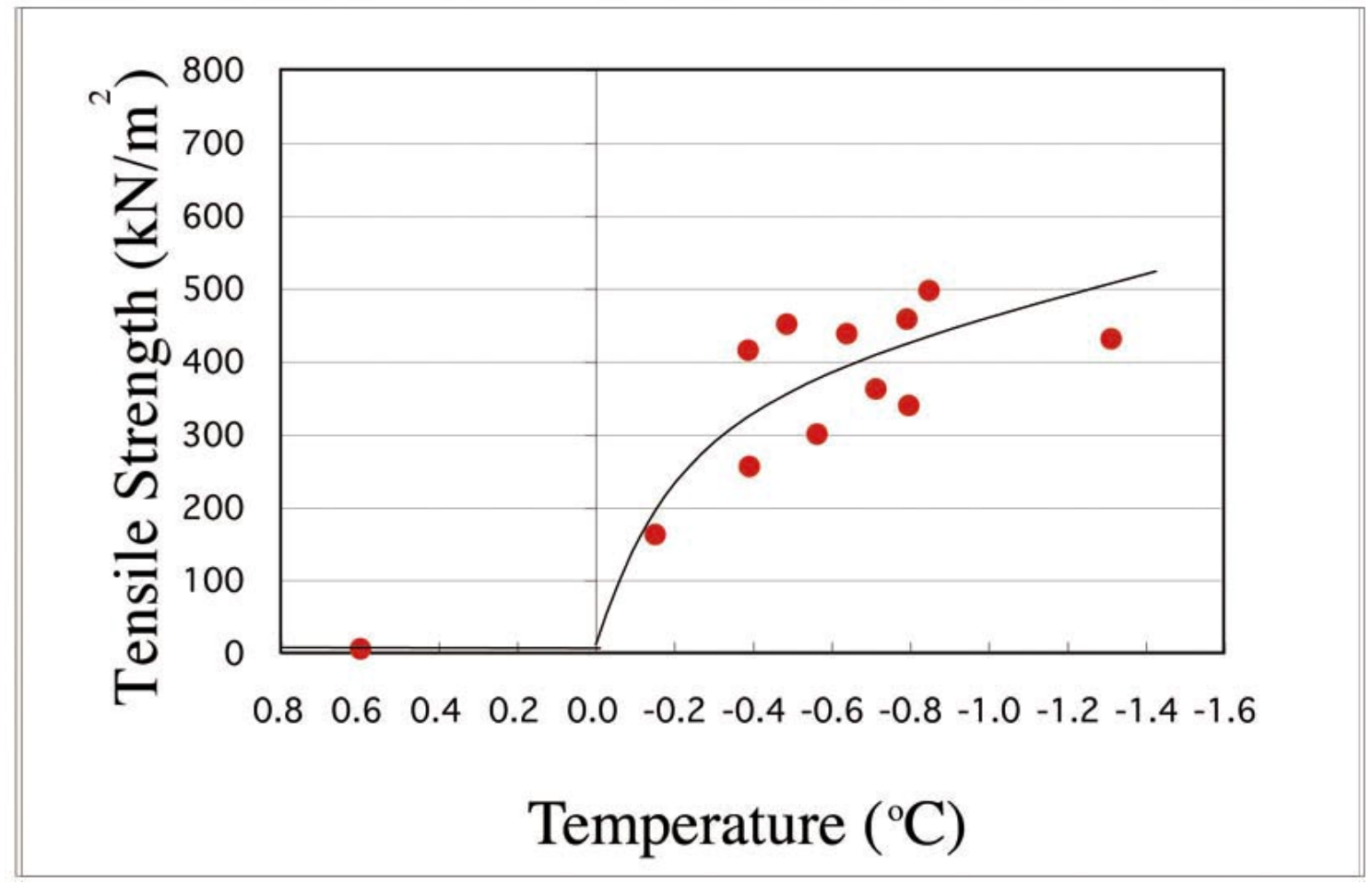

Figure 13 Tensile strength of Dotan in frozen fringe temperature 


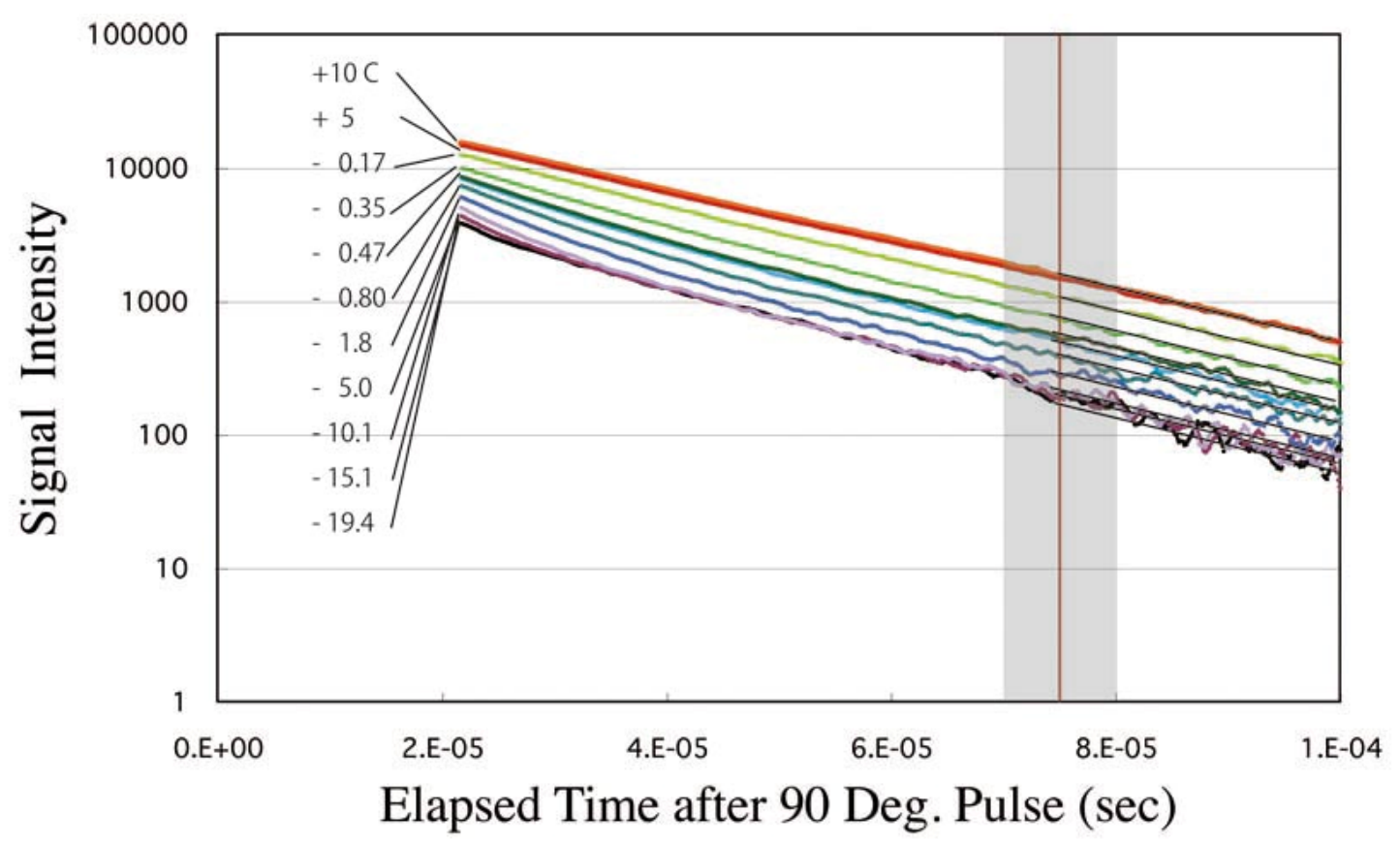

Figure 14 FID of Dotan at various temperatures, using a 90 degree pulse application with the pulse NMR method 


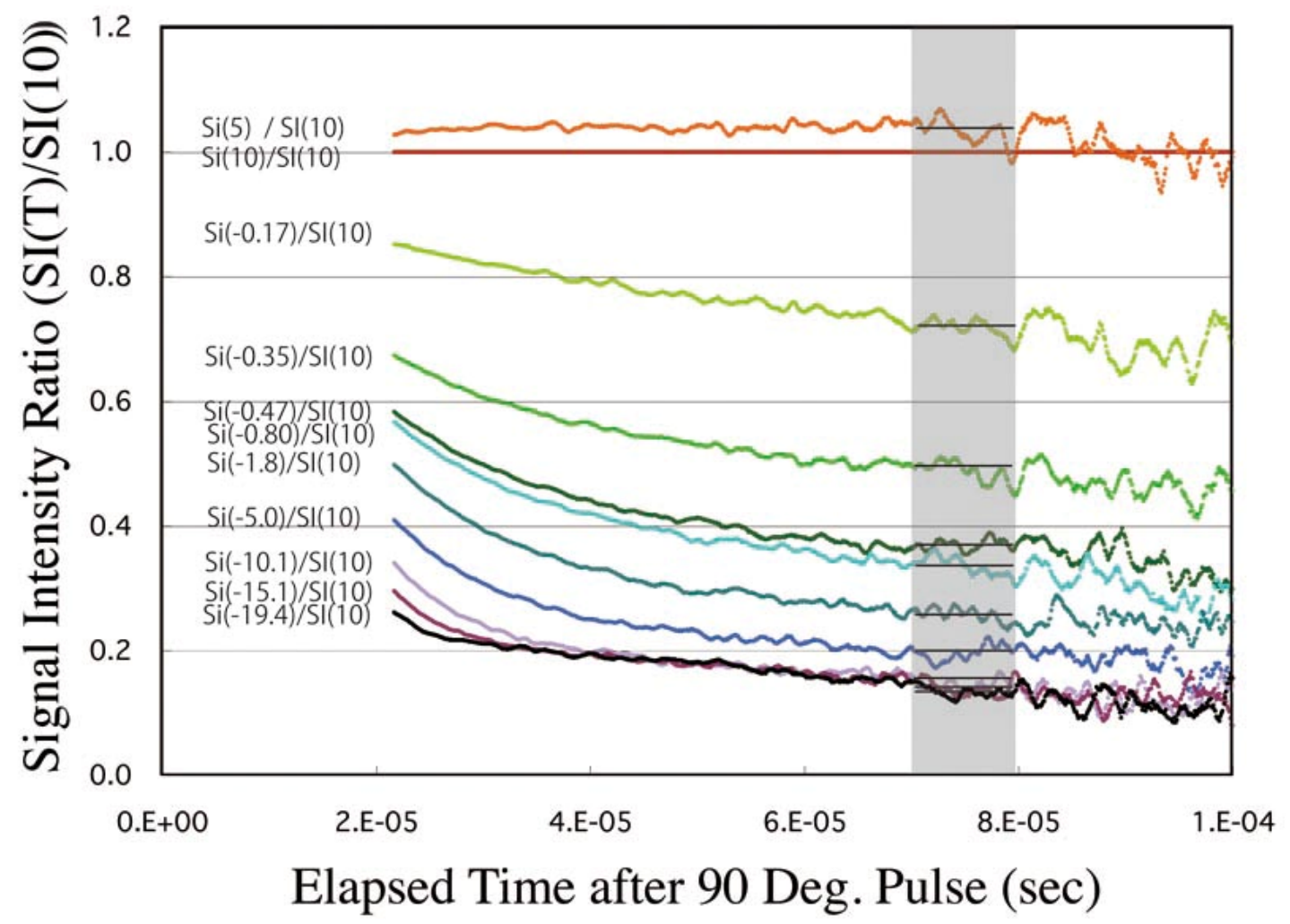

Figure 15 Verification of the NMR data using the relationship between signal intensity and water content 


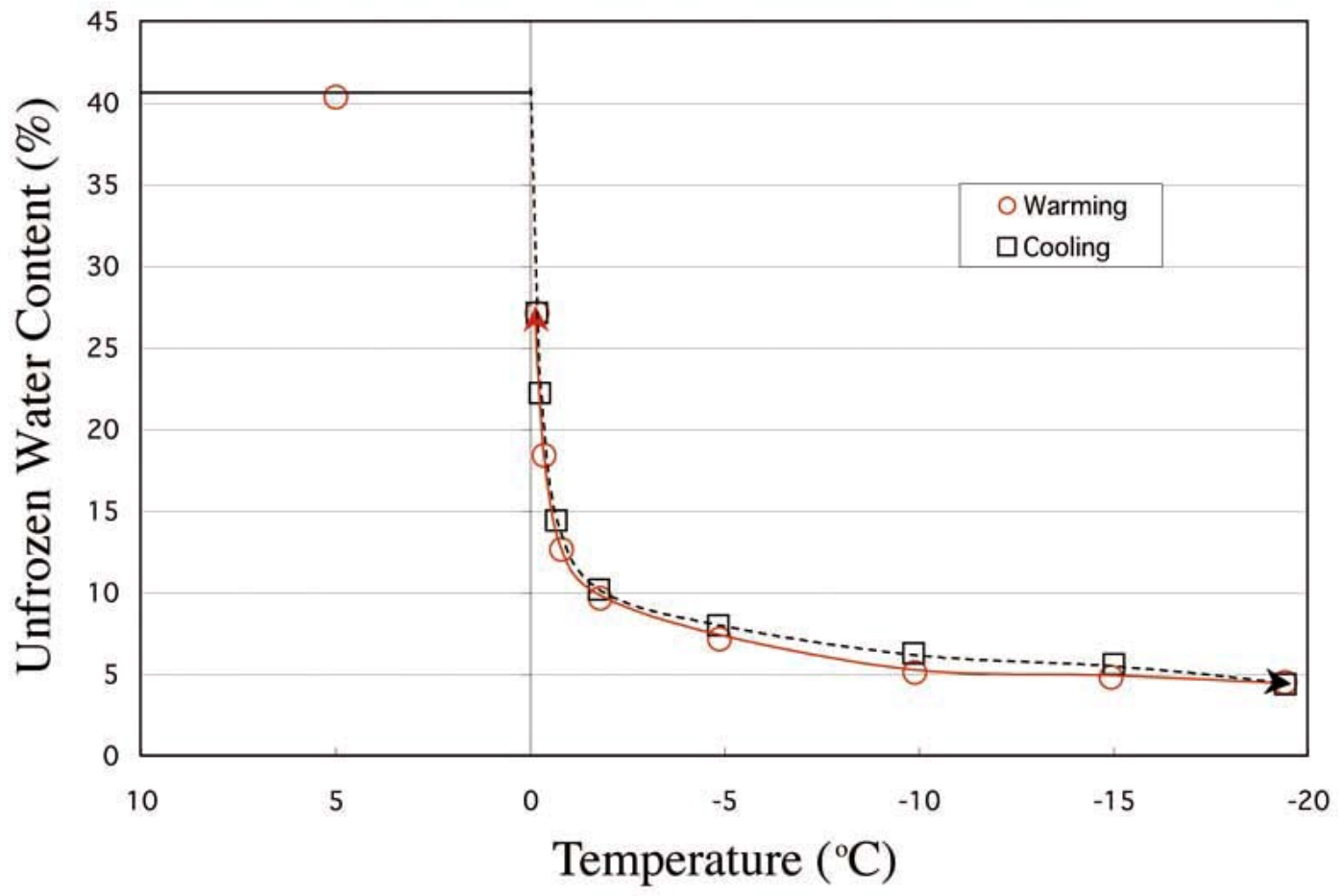

Figure 16 Unfrozen water content of Dotan measured using pulse NMR 


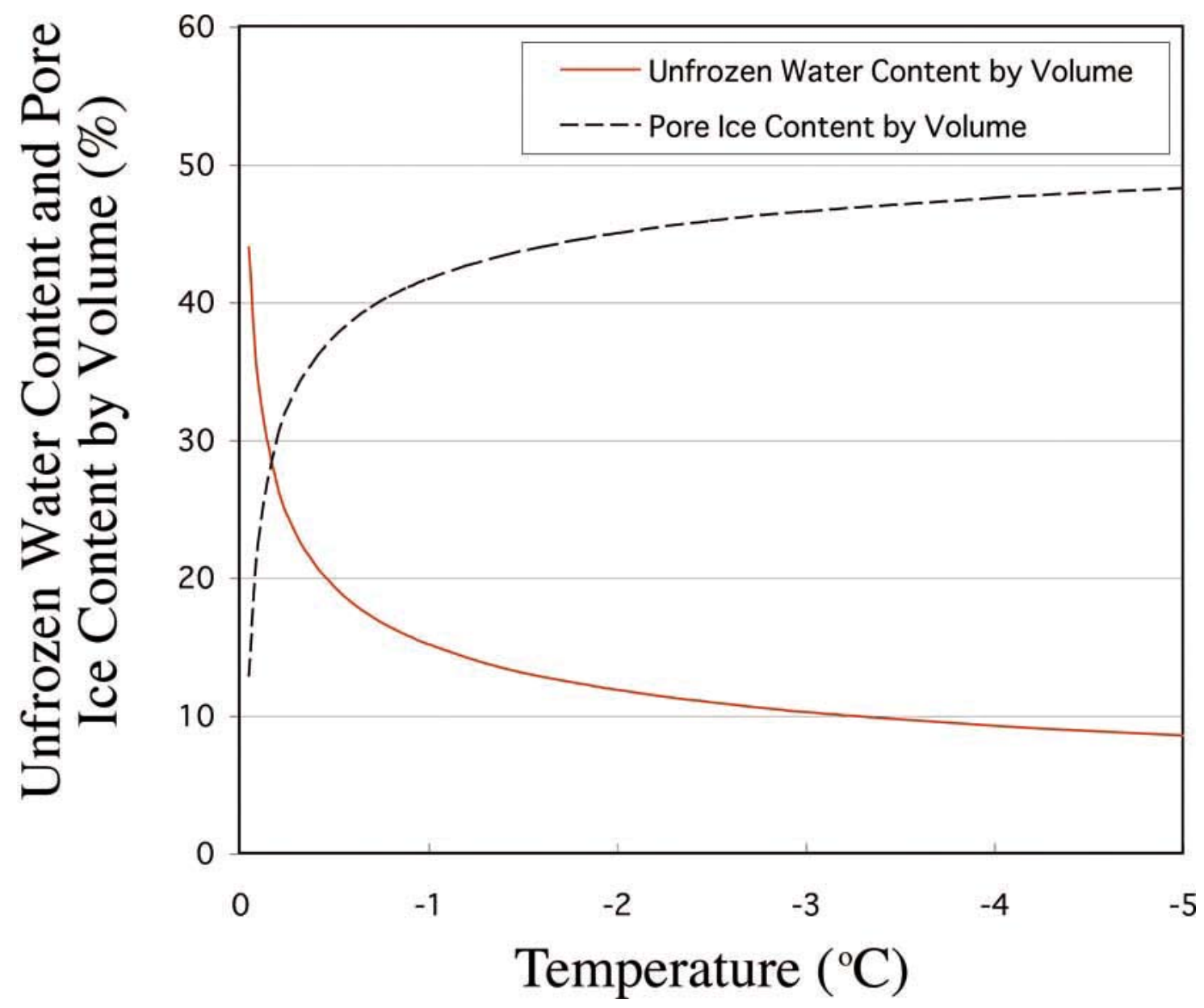

Figure 17 Measured volumetric unfrozen water content and pore ice content 


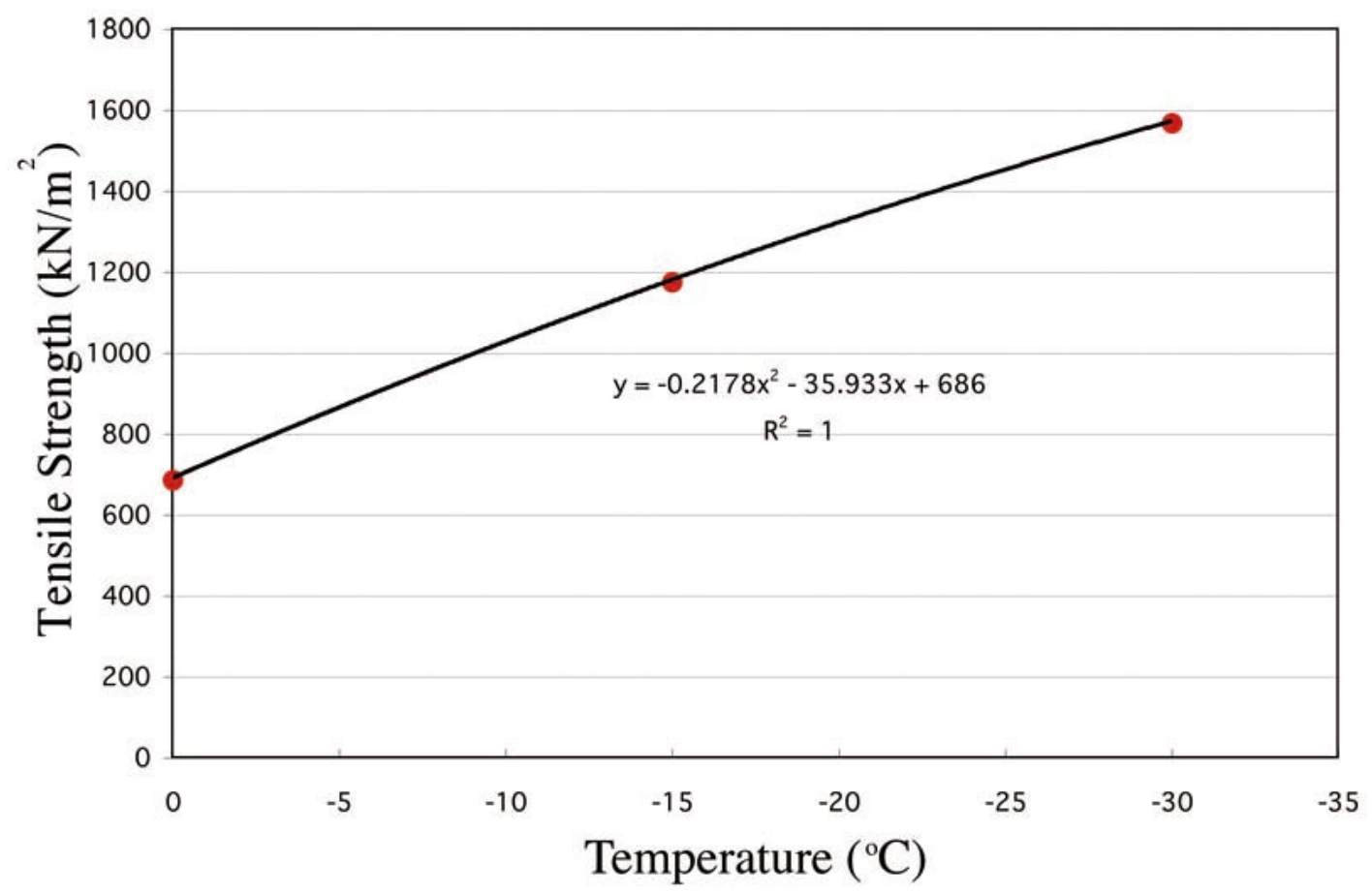

Figure 18 Ice tensile strength (adapted from Kubo 1941) 


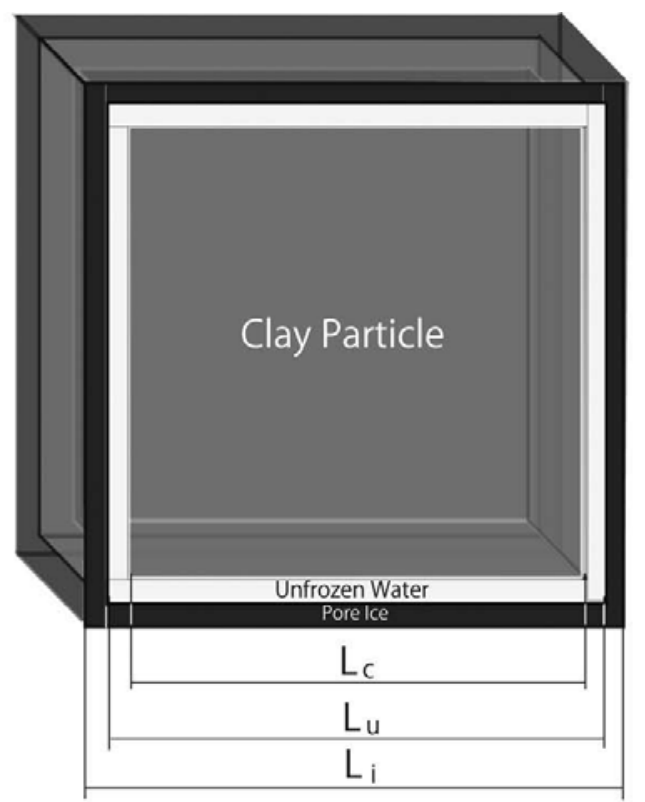

a) A unit of the model

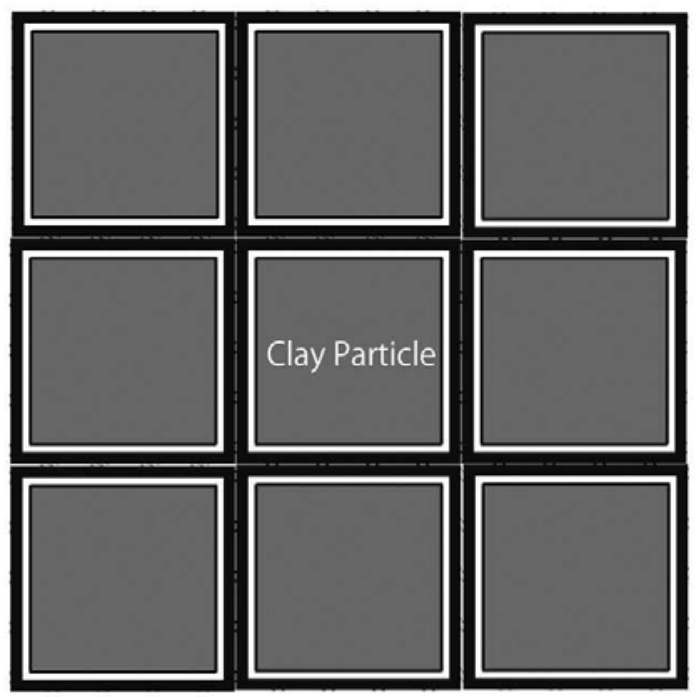

b) Array of soil cubes and pore ice framework

Figure 19 Cube soil particle model 


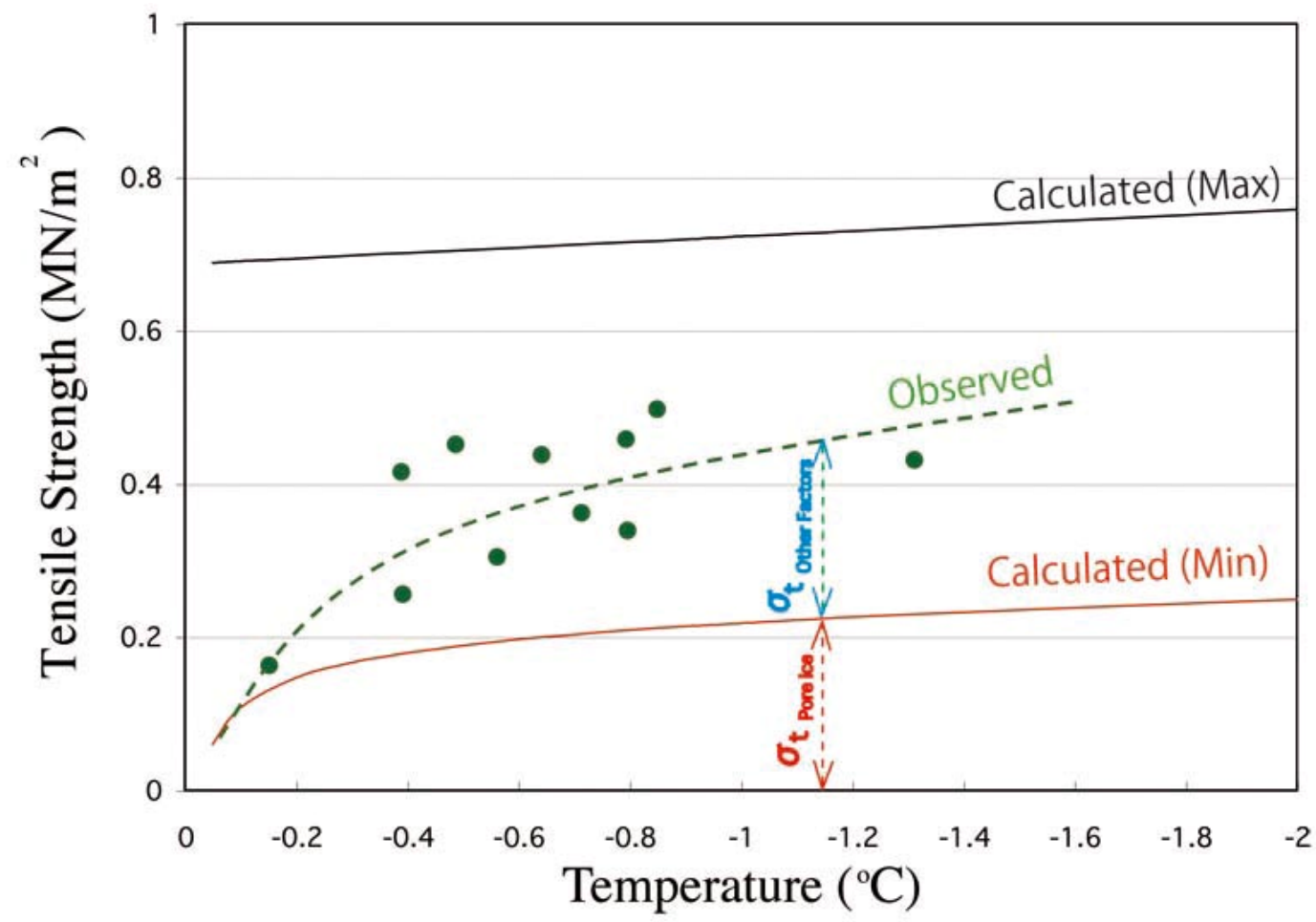

Figure 20 Comparison of the measured and calculated tensile strength of frozen Dotan and pore ice tensile strength 